Article

\title{
Clarithromycin-Loaded Poly (Lactic-co-glycolic Acid) (PLGA) Nanoparticles for Oral Administration: Effect of Polymer Molecular Weight and Surface Modification with Chitosan on Formulation, Nanoparticle Characterization and Antibacterial Effects
}

\author{
A. Alper Öztürk ${ }^{1, *(D)}$, Evrim Yenilmez ${ }^{1}$ and Mustafa Güçlü Özarda ${ }^{2}$ \\ 1 Department of Pharmaceutical Technology, Faculty of Pharmacy, Anadolu University, 26470 Eskişehir, \\ Turkey; evrimakyil@anadolu.edu.tr \\ 2 Department of Pharmaceutical Microbiology, Faculty of Pharmacy, Anadolu University, 26470 Eskişehir, \\ Turkey; mgozarda@anadolu.edu.tr \\ * Correspondence: aaozturk@anadolu.edu.tr; Tel.: +90-222-335-05-80 (ext. 3731)
}

Received: 22 August 2019; Accepted: 26 September 2019; Published: 9 October 2019

\begin{abstract}
Clarithromycin (CLR) is a member of the macrolide antibiotic group. CLR has low systemic oral bioavailability and is a drug of class II of the Biopharmaceutical Classification System. In many studies, using nanoparticles (NPs) as a drug delivery system has been shown to increase the effectiveness and bioavailability of active drug substances. This study describes the development and evaluation of poly (lactic-co-glycolic acid) (PLGA) NPs and chitosan (CS)-coated PLGA NPs for oral delivery of CLR. NPs were obtained by nanoprecipitation technique and characterized in detail, and the effect of three molecular weights $\left(\mathrm{M}_{\mathrm{w} 1}: 7.000-17.000, \mathrm{M}_{\mathrm{w} 2}: 38.000-54.000, \mathrm{M}_{\mathrm{w} 3}: 50.000-190.000\right)$ of PLGA and CS coating on particle size (PS), zeta potential (ZP), entrapment efficiency (EE\%), and release properties etc. were elucidated. Gastrointestinal stability and cryoprotectant effect tests were performed on the NPs. The PS of the prepared NPs were in the range of 178 to $578 \mathrm{~nm}$ and they were affected by the $\mathrm{M}_{\mathrm{w}}$ and CS coating. In surface-modified formulations with CS, the ZP of the NPs increased significantly to positive values. EE\% varied from $62 \%$ to $85 \%$, depending upon the $\mathrm{M}_{\mathrm{W}}$ and CS coating. In vitro release studies of CLR-loaded NPs showed an extended release up to $144 \mathrm{~h}$. Peppas-Sahlin and Weibull kinetic model was found to fit best for CLR release from NPs. By the broth microdilution test method, the antibacterial activity of the formulations was determined on Staphylococcus aureus (ATCC 25923), Listeria monocytogenes (ATCC 1911), and Klebsiella pneumoniae (ATCC 700603). The structures of the formulations were clarified by thermal (DSC), FT-IR, and ${ }^{1} \mathrm{H}-\mathrm{NMR}$ analysis. The results showed that PS, ZP, EE\%, and dissolution rates of NPs were directly related to the $\mathrm{M}_{\mathrm{w}}$ of PLGA and CS coating.
\end{abstract}

Keywords: Clarithromycin; PLGA; chitosan; nanoparticles; molecular weight; surface modification; antibacterial activity

\section{Introduction}

Oral administration remains the most appropriate, useful, and convenient route for the delivery of most pharmaceutical active agents. However, the main problem of many orally administered drugs and drug delivery systems is overcoming several obstacles before reaching their target sites. Nowadays, the research for approaches to improve the oral bioavailability of low permeable and low 
soluble compounds for oral administration continues. Using nanoparticles (NPs) as drug delivery system has taken place in the literature as one of these strategies [1]. By applying nanotechnology to medicine, NPs have been created to mimic or alter biological process [2]. NPs vary in size, although they are considered to be between 10 and 1000 nanometers $(\mathrm{nm})$ and are generally considered to be between 100 and $500 \mathrm{~nm}$ in medical applications [2,3]. By means of size, surface properties, and manipulation of the material used, NPs can be developed into therapeutic intelligent systems with increased bioavailability [2]. NP systems offer many advantages, including: improving the stability of hydrophobic drugs, rendering them suitable for oral administration with increased bioavailability; improving biodistribution and pharmacokinetics, resulting in improved efficacy; reducing side effects as a consequence of favored accumulation at target sites and decreasing toxicity by using biocompatible polymers [4]. In addition, NP systems can deliver the drug to specific tissues and provide controlled release of the drug. So, this targeted and sustained drug delivery decreases the toxicity and increases the patient's compliance with less frequent dosing [2].

Poly (lactic-co-glycolic-acid) (PLGA) is a copolymer widely used as a matrix for NPs due to its biocompatible and biodegradable characteristics. PLGA is obtained by different ratios of lactic acid and glycolic acid during polymerization resulting in different molecular weights $\left(\mathrm{M}_{\mathrm{W}}\right)$ and different physical, chemical, and physicochemical properties [5]. The mechanical strength of PLGA is particularly affected by its $M_{W}$. The $M_{w}$ of PLGA directly affects NP properties such as particle size, entrapment efficiency, release properties, and bioavailability [6]. When the studies have examined this, it has been reported that the PLGA NPs prepared with Biopharmaceutical Classification System (BCS) class-II (carvedilol [7], rifampicin [8], clotrimazole [9]), BCS class-III (Doxorubicin [10], Lamivudine [11]) and BCS Class-IV (docetaxel [12], paclitaxel [13]) drugs have increased bioavailability and also extended release.

Chitosan (CS) has been widely used in pharmaceutical and medical areas because of its favorable biological properties such as safety, biocompatibility, biodegradability, low-toxicity, bacteriostatic, fungistatic, hemostatic, anticholesterolemic, and anticancerogenic properties [14]. CS's mucoadhesive property, when positively charged, allows the interaction with negatively charged membranes and mucosa, promoting a greater interaction, adhesion, and retention of the pharmaceutical form containing CS close to the intestinal epithelium. Also, CS has the ability to temporarily open the tight junctions of the intestinal epithelium, thereby increasing the drug permeability [15].

Clarithromycin (CLR) is a semi-synthetic macrolide antibiotic used in many infectious conditions like upper and lower respiratory tracts infections, skin, ear, and other soft tissues infections caused by different bacterial groups. CLR's chemical formula is $\mathrm{C}_{38} \mathrm{H}_{69} \mathrm{NO}_{13}$ and the chemical structure of CLR is presented in Figure 1. CLR is acid stable and has a short half-life ( $3-4 \mathrm{~h})$ compatible with a twice-a-day administration [16,17]. CLR has low systemic oral bioavailability and is a drug belonging to BCS class II. Therefore, short half-life and poor systemic bioavailability of CLR limit the therapeutic efficacy of CLR in intracellular infections. So, a higher CLR dose applied for a longer time to achieve a therapeutic effect that may lead to side and toxic effects such as hepatotoxicity [16,17].

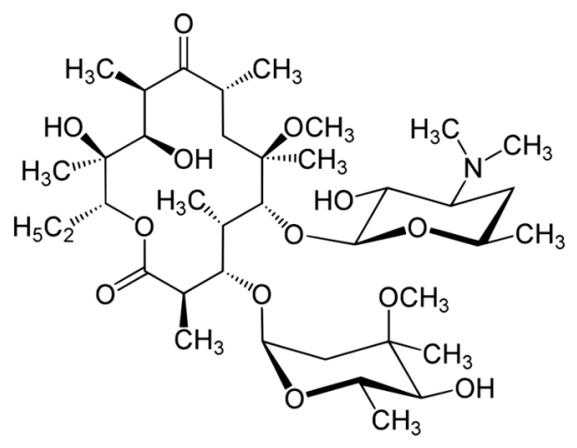

Figure 1. Chemical structure of clarithromycin (CLR). 
So far, CLR-loaded PLGA NPs have been the subject of research in some studies. In one of these studies, NPs were prepared with three different drug: polymer ratios using only Resomer ${ }^{\circledR}$ RG 502 (lactic acid: glycolic acid ratio 50:50, average $\mathrm{M}_{\mathrm{w}}$ : 12.000) by nanoprecipitation technique [18]. The same study was then supported by intestinal permeability tests [1]. In another study, CLR-loaded PLGA microspheres were prepared using only one type PLGA (lactic acid: glycolic acid ratio 75:25, $\mathrm{M}_{\mathrm{W}}$ 15.000-30.000) by modified O/W single emulsion-solvent evaporation technique [19]. In another study, CLR-loaded PLGA NPs were prepared by solvent evaporation technique with only one type of PLGA (lactic acid: glycolic acid ratio 50:50) and different drug: polymer ratios [20]. As can be seen from the previous studies, no studies have examined the effect of $\mathrm{M}_{\mathrm{w}}$ of PLGA polymer on CLR-loaded NPs. [10]. The lactide:glycolide ratio of the PLGA types used in our study was 50:50. The PLGA polymer types were all different in their physical and appearance properties and the lactide:glycolide ratio can completely change the properties expected from the formulation. It is also the fact that the device and surfactant used in preparing the formulation changes the properties of the prepared formulation [11]. In addition, as can be seen from previous studies, no method used in this study is similar to others and in our study chitosan modification was also made to the formulations.

In this study, we aimed to prepare CLR-loaded PLGA NPs with enhanced bioavailability and increased antibacterial effect with low dose use. For this purpose, we examined three different $M_{w}$ of PLGA and CS coatings. We prepared three different PLGA NPs and three different CS-coated PLGA NPs by the 'nanoprecipitation' technique. The effects of the $\mathrm{M}_{\mathrm{w}}$ of PLGA and CS coating on the properties of NPs such as particle size, zeta potential, entrapment efficiency and release rates are discussed in detail. Once these effects were determined, the release kinetics of both burst effect and total release time were examined based on the release results. The crystalline properties of all NPs were then examined by thermal (DSC), FT-IR, and ${ }^{1} \mathrm{H}-\mathrm{NMR}$ analysis and finally, antibacterial activity against Staphylococcus aureus (ATCC 25923), Enterococcus faecalis (ATCC 29212), Listeria monocytogenes (ATCC 1911), and Klebsiella pneumoniae (ATCC 700603) was determined by microdilution method. Within the scope of the study, using different $\mathrm{M}_{\mathrm{w}}$ of PLGA and coating the formulations with CS is an innovative approach for CLR-loaded PLGA NPs and will add new information to the scientific world.

\section{Materials and Methods}

\subsection{Materials}

Clarithromycin was a kind gift from Sanovel (Istanbul, Turkey). Resomer ${ }^{\circledR}$ RG $502 \mathrm{H}$ [Poly (D,L-lactide-co-glycolide), acid-terminated, lactide:glycolide 50:50, $\left.\mathrm{M}_{\mathrm{W}}: 7.000-17.000\right]$, Resomer ${ }^{\circledR} \mathrm{RG}$ $503 \mathrm{H}$ [Poly (D,L-lactide-co-glycolide), acid-terminated, lactide:glycolide 50:50, $\mathrm{M}_{\mathrm{w}}$ : 24.000-38.000], Resomer ${ }^{\circledR}$ RG $504 \mathrm{H}$ [Poly(D,L-lactide-co-glycolide), acid-terminated, lactide:glycolide 50:50, $\mathrm{M}_{\mathrm{w}}$ : 38.000-54.000], and Span ${ }^{\circledR} 60$ were purchased from Sigma-Aldrich (St. Louis, MO, USA). Low $\mathrm{M}_{\mathrm{w}}$ chitosan [Deacetylated chitin/Poly (D-glucosamine), $\mathrm{M}_{\mathrm{W}}$ : 50.000-190.000 Da, viscosity: 20-300 cP] was purchased from Sigma (Steinheim, Germany). Pluronic ${ }^{\circledR}$ F-68 was purchased from Alfa-Aesar (Kandel, Germany). All other chemicals used were of analytical grade.

\subsection{Preparation of PLGA Nanoparticles and Surface Modification with Chitosan}

PLGA-based NPs were prepared by following the nanoprecipitation technique with some modifications [7]. Briefly, a weighed amount of PLGA $(90 \mathrm{mg})$ was dissolved in $3 \mathrm{~mL}$ acetone together with Span ${ }^{\circledR} 60(30 \mathrm{mg})$. Next, $3 \mathrm{~mL}$ of this solution was added dropwise at a rate of $5 \mathrm{~mL} \cdot \mathrm{h}^{-1}$ into $10 \mathrm{~mL}$ of Pluronic ${ }^{\circledR}$ F- 68 aqueous solution $(0.5 \%, w / v)$ under magnetic stirring. Acetone was then allowed to evaporate at room temperature under magnetic stirring for $4 \mathrm{~h}$. The resulting aqueous dispersion was centrifuged to collect the NPs (11.000 rpm, $45 \mathrm{~min}, 4^{\circ} \mathrm{C}$ ) (Hettich Rotina-420R, Tuttlingen, Germany). After the NPs were collected, $5 \mathrm{~mL}$ of distilled water was added in order to wash the particles. The NPs dispersed in water were again subjected to the above-mentioned centrifugation process. This process was repeated twice to wash the NPs. 
For CLR-loaded PLGA-based NP preparation, briefly, the procedure started by adding $9 \mathrm{mg}$ CLR to organic phase. Then, $3 \mathrm{~mL}$ of such solution with drugs were added drop-wise at rate $5 \mathrm{~mL} . \mathrm{h}^{-1}$ into $10 \mathrm{~mL}$ of Pluronic ${ }^{\circledR} \mathrm{F}-68$ aqueous solution $(0.5 \%, w / v)$ under magnetic stirring. Acetone was then allowed to evaporate at room temperature under magnetic stirring for $4 \mathrm{~h}$. The resulting aqueous dispersion was centrifuged to collect the NPs (11.000 rpm, $45 \mathrm{~min}, 4^{\circ} \mathrm{C}$ ) (Hettich Rotina-420R, Tuttlingen, Germany). This process was repeated twice to wash the NPs.

The above procedure was applied with minor modifications when preparing CS-coated formulations. In the CS-coated formulations, the aqueous phase consisted of $10 \mathrm{~mL}$ of CS solution $(0.25 \%$, $w / v)$ and Pluronic ${ }^{\circledR}$ F-68 $(0.5 \%, w / v)$, both prepared in $2 \%$ acetic acid $(v / v)[15,21,22]$. All remaining procedures are the same as above and the formulation ingredients are presented in Table 1.

Table 1. Formulation ingredients.

\begin{tabular}{lcccccccc}
\hline Code & $\mathbf{5 0 2} \mathbf{H}^{*}$ & $\mathbf{5 0 3} \mathbf{H}^{*}$ & $\mathbf{5 0 4} \mathbf{H}^{*}$ & Span $\mathbf{6 0}$ & $\mathbf{A C N}{ }^{*}$ & $\mathbf{C L R}{ }^{*}$ & $\begin{array}{c}\text { Pluronic F-68 } \\
\mathbf{( 0 . 5 \% )}\end{array}$ & $\begin{array}{c}\text { Chitosan } \\
\mathbf{( 0 . 2 5} \mathbf{\%})\end{array}$ \\
\hline $502 \mathrm{H}-B l a n k$ & $90 \mathrm{mg}$ & - & - & $30 \mathrm{mg}$ & $3 \mathrm{~mL}$ & - & $10 \mathrm{~mL}$ & - \\
$503 \mathrm{H}-B l a n k$ & - & $90 \mathrm{mg}$ & - & $30 \mathrm{mg}$ & $3 \mathrm{~mL}$ & - & $10 \mathrm{~mL}$ & - \\
$504 \mathrm{H}-B l a n k$ & - & - & $90 \mathrm{mg}$ & $30 \mathrm{mg}$ & $3 \mathrm{~mL}$ & - & $10 \mathrm{~mL}$ & - \\
\hline $502 \mathrm{H}$ & $90 \mathrm{mg}$ & - & - & $30 \mathrm{mg}$ & $3 \mathrm{~mL}$ & $9 \mathrm{mg}$ & $10 \mathrm{~mL}$ & - \\
$503 \mathrm{H}$ & - & $90 \mathrm{mg}$ & - & $30 \mathrm{mg}$ & $3 \mathrm{~mL}$ & $9 \mathrm{mg}$ & $10 \mathrm{~mL}$ & - \\
$504 \mathrm{H}$ & - & - & $90 \mathrm{mg}$ & $30 \mathrm{mg}$ & $3 \mathrm{~mL}$ & $9 \mathrm{mg}$ & $10 \mathrm{~mL}$ & - \\
\hline CS-502H-Blank & $90 \mathrm{mg}$ & - & - & $30 \mathrm{mg}$ & $3 \mathrm{~mL}$ & - & - & $10 \mathrm{~mL}$ \\
CS-503H-Blank & - & $90 \mathrm{mg}$ & - & $30 \mathrm{mg}$ & $3 \mathrm{~mL}$ & - & - & $10 \mathrm{~mL}$ \\
CS-504H-Blank & - & - & $90 \mathrm{mg}$ & $30 \mathrm{mg}$ & $3 \mathrm{~mL}$ & - & - & $10 \mathrm{~mL}$ \\
\hline CS-502H & $90 \mathrm{mg}$ & - & - & $30 \mathrm{mg}$ & $3 \mathrm{~mL}$ & $9 \mathrm{mg}$ & - & $10 \mathrm{~mL}$ \\
CS-503H & - & $90 \mathrm{mg}$ & - & $30 \mathrm{mg}$ & $3 \mathrm{~mL}$ & $9 \mathrm{mg}$ & - & $10 \mathrm{~mL}$ \\
CS-504H & - & - & $90 \mathrm{mg}$ & $30 \mathrm{mg}$ & $3 \mathrm{~mL}$ & $9 \mathrm{mg}$ & - & $10 \mathrm{~mL}$ \\
\hline
\end{tabular}

* 502 H: Resomer RG 502 H, 503 H: Resomer RG 503 H, 504 H: Resomer RG 504 H, ACN: acetone, CLR: clarithromycin, Chitosan solution: including Pluronic F-68 (0.5\%).

\subsection{Characterization of Nanoparticles}

\subsubsection{Particle Size, Polydispersity Index, Zeta Potential}

The particle size (PS) and polydispersity index (PDI) of NPs were measured using dynamic light scattering technique on the Zetasizer Nano (Zetasizer Nano ZS, Malvern Instruments, Malvern, UK). PS and PDI of NPs prepared were measured by dispersing the formulation in distilled water. Zeta potential (ZP) was determined using the same instrument in a disposable folded capillary zeta cell at $25{ }^{\circ} \mathrm{C}$ room temperature and diluted with distilled water. For statistical analysis all samples were measured in triplicate and the average values and standard deviation of the measurements were calculated.

\subsubsection{Assessment of Cryoprotectant Effect on Nanoparticles}

Some experiments were carried out on PLGA NPs and CS-coated PLGA NP formulations to determine storage and lyophilization conditions. Following PS measurement of fresh formulations, they were centrifuged and the supernatants were discarded. The resulting particles were added to 1 $\mathrm{mL}$ of $5 \%(w / v)$ trehalose solution and the PS measurement was performed again. The dispersion was then divided into five equal portions ( $200 \mu \mathrm{L} \mathrm{NP}$ suspension) in 5 Eppendorf tubes. While no trehalose solution was added to tube $1,150 \mu \mathrm{L}, 300 \mu \mathrm{L}, 450 \mu \mathrm{L}$, and $600 \mu \mathrm{L}$ trehalose solution $(5 \% w / v)$ were added to other tubes, respectively. All formulations were then frozen at $-20^{\circ} \mathrm{C}$ and then lyophilization (Scanvac CoolSafePro Labogene, Lillerød, Denmark) was performed for all tubes, the dry particles were removed from the machine and dispersed in $1 \mathrm{~mL}$ of water, followed by PS analysis [5,7]. 


\subsubsection{Evaluation of Gastrointestinal Stability of Nanoparticles}

Before testing the gastrointestinal stability of NPs, solutions simulating gastrointestinal fluids were prepared. The solutions were $\mathrm{pH} 1.2$ solution; intestinal fluid phosphate buffer solution ( $\mathrm{pH}$ 6.8); phosphate buffer solution ( $\mathrm{pH} 7.4$ ); and distilled water. All three solutions and distilled water were placed in a shaking water bath at a stirring speed of $40 \mathrm{rpm}$ at a temperature of $37^{\circ} \mathrm{C}$ to simulate the gastric medium. One set of formulations $(502 \mathrm{H}, 503 \mathrm{H}, 504 \mathrm{H}, \mathrm{CS}-502 \mathrm{H}, \mathrm{CS}-503 \mathrm{H}, \mathrm{CS}-504 \mathrm{H})$ was prepared and dispersed in trehalose solution at $5 \%(w / v)$ concentration. Then, $1 \mathrm{~mL}$ of this dispersion was added to solutions incubated at $37 \pm 1{ }^{\circ} \mathrm{C}$. Samples were collected after preincubation periods of 3 , 9, and $24 \mathrm{~h}$ and centrifuged at $4.000 \mathrm{rpm}$ for $5 \mathrm{~min}$ to precipitate NPs. Finally, the average PS of the NPs was determined [5,7]. This work was performed on fresh nanoparticle batches.

\subsubsection{High Performance Liquid Chromatography (HPLC) Conditions}

The amount of CLR loaded into NPs and dissolution study of each formulation was performed using HPLC (Shimadzu Corporation, Kyoto, Japan) with reversed-phase Inert Sustain $\mathrm{C}_{18}(5.0 \mu \mathrm{m}$, $150 \mathrm{~mm} \times 4.6 \mathrm{~mm}$, GL Sciences Inc., Torrance, CA, USA) column. In the HPLC system, the mobile phase was acetonitrile: $0.035 \mathrm{M}$ potassium dihydrogen phosphate buffer $\left(\mathrm{KH}_{2} \mathrm{PO}_{4}\right)(55: 45 \mathrm{v} / \mathrm{v})$ mixture, the flow rate was $1 \mathrm{~mL} \cdot \mathrm{min}^{-1}$, while detection was performed at $200 \mathrm{~nm}$ at $30^{\circ} \mathrm{C}$. Injection volume was $25 \mu \mathrm{L}$. Mobile phase was prepared daily, degassed by sonication, and filtered through $0.45 \mu \mathrm{m}$ membrane filter before the experiment. The method was validated for precision, accuracy, specificity, and linearity [23].

\subsubsection{Entrapment Efficiency}

For entrapment efficiency, the method of extraction of CLR from NPs was used [5]. Accurately weighed $(5 \mathrm{mg})$ NPs were dissolved in ethyl acetate. The resultant samples were filtered through $0.45 \mu \mathrm{m}$ membrane filters and analyzed using HPLC. The entrapment efficiency (EE\%) of NPs was calculated by Equation (1) [7].

$$
\mathrm{EE} \%=\left[\frac{\text { Actual amount of CLR loaded in NPs }}{\text { Theoretical amount of CLR loaded in NPs }}\right] \times 100 .
$$

\subsubsection{Dissolution and Release Kinetic Evaluation}

In vitro dissolution study was performed in intestinal fluid phosphate buffer $\mathrm{pH} 6.8$ containing $1 \%$ Tween ${ }^{\circledR} 80$ to retain sink conditions maintained at $37 \pm 1{ }^{\circ} \mathrm{C}$ and $50 \mathrm{rpm}$ using a USP Type II dissolution apparatus (PTWS 820D Pharma Test USP/EP Dissolution Testing Instrument, Hainburg, Germany). Pure CLR ( $5 \mathrm{mg}$ ) and equivalent NP formulations (equivalent $5 \mathrm{mg}$ CLR) were placed in a cellulose acetate dialysis bag (dialysis tubing cellulose membrane, molecular weight cut-off: 14.000, Sigma-Aldrich, USA). After the addition of $1 \mathrm{~mL}$ of dissolution medium, the bag was sealed at both ends with special clamps for dissolution. After all the dialysis bags were closed, they were all immersed in the $500 \mathrm{~mL}$ of dissolution medium at the same time. Samples of the medium $(5 \mathrm{~mL})$ were withdrawn and replaced with fresh medium at 1,3,6, 9, 12, 24, 48, 72, 96, 120, and $144 \mathrm{~h}[24,25]$. CLR concentration in the samples was analyzed by HPLC. The dissolution study was repeated three times for all NP formulations and pure CLR and the results were calculated as mean \pm SD. The results were then plotted as cumulative release.

Data obtained in the in vitro dissolution studies were further investigated for release kinetics using DDSolver software program. DDSolver computer program was used to shorten the calculation time, eliminate calculation errors, and determine the correct release profile [26]. DDSolver software program was used for evaluating Higuchi, Korsmeyer-Peppas, Baker-Lonsdale, Peppas-Sahlin, and Weibull models. 


\subsection{Solid State Characterization of Nanoparticles}

\subsubsection{Thermal (DSC) Analysis}

The physical states of NPs were characterized by differential scanning calorimetry (DSC) (DSC-60, Shimadzu Scientific Instruments, Columbia, MI, USA). Aluminum crucibles with $3 \mathrm{mg}$ samples were analyzed under nitrogen gas $\left(50 \mathrm{~mL} \cdot \mathrm{min}^{-1}\right)$ and heating rate of $10^{\circ} \mathrm{C} \cdot \mathrm{min}^{-1}$ at a temperature range of 30 and $300^{\circ} \mathrm{C}$. Pure CLR and blank formulation were also analyzed and were used as references.

\subsubsection{FT-IR Analysis}

FT-IR spectra of NPs were recorded using Shimadzu IR Prestige-21 (Shimadzu Corporation, Kyoto, Japan) at the wavelength range of $4000-500 \mathrm{~cm}^{-1}$. Pure CLR and blank formulations were also analyzed and were used as references.

\subsection{3. ${ }^{1} \mathrm{H}-\mathrm{NMR}$ Analysis}

${ }^{1} \mathrm{H}-\mathrm{NMR}$ analyses were performed using UltraShield ${ }^{\mathrm{TM}}$ CPMAS NMR (Brucker, Rheinstetten, Germany). Samples were prepared by dissolving formulations in deuterated chloroform $\left(\mathrm{CDCI}_{3}\right)$. Pure CLR and blank formulations were also analyzed and were used as references.

\subsection{Antimicrobial Activity Test}

\subsubsection{Microorganisms}

The following organisms were used in this study: Staphylococcus aureus (ATCC 25923), Enterococcus faecalis (ATCC 29212), Listeria monocytogenes (ATCC 1911), Klebsiella pneumoniae (ATCC 700603). All the bacterial strains were obtained from the ATCC (Rockville, MD, USA). The bacteria were in liquid nutrient broth (Merck) for fresh pure cultures.

\subsubsection{Inoculum}

The standardization of the bacterial cell number used for susceptibility testing is of critical importance for obtaining accurate and reproducible results. The recommended final inoculum size for broth dilution is $5 \times 10^{5}$ colony-forming units (CFU) per mL. For that reason, all inocula were set in $0.5 \mathrm{McF}$ arland standard with McFarland Tube Densitometer for accurate and reproducible results.

\subsubsection{Broth Microdilution Method}

Derivatives of substances were dissolved/suspended in DMSO and concentrations were prepared on ranging from 0.49 to $250 \mu \mathrm{L} \cdot \mathrm{mL}^{-1}$. The prepared concentrations were distributed in duplicate $100 \mu \mathrm{l}$ for each well on the 96-well plate. After that, fresh pure bacterial cultures, which were set in 0.5 McFarland standard in Mueller Hinton Broth (Sigma-Aldrich), were added at concentrations of $100 \mu \mathrm{L}$. After adding the bacterial cultures, final concentrations for all derivatives ranged from 250 to $0.49 \mu \mathrm{L} \cdot \mathrm{mL}^{-1}$. At the end of this process, all plates were incubated for $24 \mathrm{~h}$. All steps were performed as recommended by CLSI protocol.

\subsection{Software Program}

Microsoft Excel and DDSolver were employed for calculations.

\section{Results and Discussion}

\subsection{Preparation of PLGA Nanoparticles and Surface Modification with Chitosan}

PLGA is widely used in drug research due to the biocompatibility, biodegradability, and multidimensional degradation kinetics. The structural properties of PLGA, and especially 
its $\mathrm{M}_{\mathrm{w}}$, affect many parameters in the properties of the NP formulations. The $\mathrm{M}_{\mathrm{w}}$, in particular, affects the biological activity due to particle size, entrapment efficiency, release and release kinetics [27]. For this purpose, three different $\mathrm{M}_{\mathrm{W}}$ of PLGA were used for prepared PLGA NPs. In order to investigate the effects of $\mathrm{M}_{\mathrm{W}}$ on PLGA NP properties, three different formulations were prepared. The differences between the formulations were determined primarily by preparing formulations containing only Resomer ${ }^{\circledR}$ RG 502 H (502H-coded formulations), only Resomer ${ }^{\circledR}$ RG 503 H (503H-coded formulations), and only Resomer ${ }^{\circledR}$ RG $504 \mathrm{H}$ (504H-coded formulations).

The surface modification of the PLGA NPs was performed by CS, because the mucosal adhesive of CS had a positive ZP and CS interacted with negatively charged membranes and mucosa [15]. When the literature was examined, better results were obtained by surface modification with CS during NP preparation compared to after preparation [22]. Based on this literature information, we did not expose our prepared NPs to CS solution so as to avoid damage, we prepared them directly in CS solution. We modified the surface properties of all NPs prepared with different $\mathrm{M}_{\mathrm{W}}$ of PLGA using CS (CS-502H, CS-503H, and CS-504H coded formulations). NP properties were examined in detail in terms of pharmaceutical nanotechnology, followed by antibacterial activity for all formulations.

\subsection{Characterization of nanoparticles}

\subsubsection{Particle Size, Polydispersity Index, Zeta Potential}

PS, PDI, and ZP results are given in Table 2. The average PS of blank PLGA NPs varied between $142.0 \mathrm{~nm}$ and $154.4 \mathrm{~nm}$, whereas the average PS of CLR-loaded PLGA NPs varied between $178.7 \mathrm{~nm}$ and $198.9 \mathrm{~nm}$. The first thing that stands out in PS results is that PS increases with CLR loading. When a previous study with PLGA was reviewed, it was reported that PS increased when the active drug substance was loaded into NPs [5]. Another noteworthy point is that the $\mathrm{M}_{\mathrm{w}}$ of PLGA affects PS results. When PS results were examined, the highest PS was obtained in the NP prepared with the lowest $\mathrm{M}_{\mathrm{W}}$ of PLGA and the lowest PS was obtained in the NP prepared with the highest $\mathrm{M}_{\mathrm{W}}$ of PLGA. The PS of NPs prepared with ResomerRG's decreased with increase in $M_{W}\left(M_{W} 502 H<M_{W} 503 \mathrm{H}<\right.$ $\left.M_{W} 504 \mathrm{H}\right)$. These PS results can be explained by the hydrophobicity of the PLGA employed. At high $M_{w}$, higher hydrophobicity and smaller PS were obtained due to longer aliphatic chains [28,29]. It was found that the addition of CS led to an increase in PS. PSs of NPs prepared with CS increased more than twofold compared to those prepared with PLGA alone. This may be explained due to CS-related viscosity increase, which reduces the shear stress during mixing of the emulsion on the magnetic stirrer and then leads to an increase in the PS of the emulsion droplets [15]. Similar results were obtained in literature $[28,30]$. Nonetheless, surface modification of NPs with hydrophilic components like CS is expected to improve their cellular uptake, as well as avoid the opsonization process, regardless of the reported size increase [28]. For the oral administration of CLR-loaded NPs, all NPs have desirable PS according to literature [31]. NPs prepared in this study were able to reach microcirculation by the blood capillaries or penetrate through pores present in the surfaces and membranes [15,31].

The PDI, which is a ratio that gives information about the homogeneity of the PS distribution in a given system, reflects the quality of the NP dispersion within the range of $0.0-1.0$. PDI values $\leq 0.1$ indicate the highest quality of dispersion. Most researchers recognize PDI values $\leq 0.3$ as optimum values; however, values $\leq 0.5$ are also acceptable [32]. According to literature, quality and monodisperse PLGA NPs and CS-coated PLGA NPs have been prepared. 
Table 2. Particle size (PS), polydispersity index (PDI), zeta potential (ZP), and entrapment efficiency $(\mathrm{EE} \%)$ results.

\begin{tabular}{lcccc}
\hline Code & PS * & PDI * & ZP * & EE\% * \\
\hline 502H-Blank & $154.4 \pm 5.4$ & $0.154 \pm 0.086$ & $-26.4 \pm 0.7$ & - \\
503H-Blank & $143.3 \pm 1.3$ & $0.161 \pm 0.024$ & $-34.8 \pm 1.5$ & - \\
504H-Blank & $142.0 \pm 2.6$ & $0.160 \pm 0.082$ & $-36.7 \pm 0.5$ & - \\
\hline 502H & $198.9 \pm 1.5$ & $0.286 \pm 0.067$ & $-33.2 \pm 1.8$ & $85.199 \pm 2.138$ \\
$503 H$ & $191.3 \pm 2.9$ & $0.216 \pm 0.008$ & $-31.0 \pm 1.6$ & $77.836 \pm 4.614$ \\
$504 H$ & $178.7 \pm 1.6$ & $0.139 \pm 0.060$ & $-33.5 \pm 1.2$ & $74.627 \pm 3.390$ \\
\hline CS-502H-Blank & $441.1 \pm 7.9$ & $0.300 \pm 0.056$ & $+75.1 \pm 0.9$ & - \\
CS-503H-Blank & $419.0 \pm 9.9$ & $0.314 \pm 0.058$ & $+77.5 \pm 4.2$ & - \\
CS-504H-Blank & $407.9 \pm 3.6$ & $0.334 \pm 0.065$ & $+71.1 \pm 1.8$ & - \\
\hline CS-502H & $499.9 \pm 7.4$ & $0.311 \pm 0.110$ & $+75.0 \pm 1.9$ & $63.460 \pm 3.910$ \\
CS-503H & $525.2 \pm 2.9$ & $0.326 \pm 0.120$ & $+76.6 \pm 1.65$ & $62.771 \pm 1.911$ \\
CS-504H & $578.3 \pm 6.8$ & $0.321 \pm 0.076$ & $+75.8 \pm 0.9$ & $62.463 \pm 0.026$
\end{tabular}

* Results given as mean \pm SD, PS: Particle size (nm), PDI: Polydispersity index, ZP: Zeta potential (mV), EE\%: Entrapment efficiency (\%).

When Table 2 is examined, negative ZP values are observed in uncoated PLGA NPs. ZP was observed in the range of -26.4 to $-36.7 \mathrm{mV}$ and -31.0 to $-33.5 \mathrm{mV}$, respectively, in blank PLGA NPs and CLR-loaded NPs. PLGA in neutral medium has negative surface potential, attributed to the terminal carboxyl groups, and this could be verified by the ZP of negative obtained in uncoated PLGA NPs [15]. A colloidal system having $\pm 30 \mathrm{mV}$ as the $\mathrm{ZP}$ value is considered a stable formulation if dispersed as a colloidal dispersion in a liquid [33]. ZPs between -5.0 and $-15.0 \mathrm{mV}$ are in the limited flocculation zone; and the maximum flocculation zone between -5.0 and $-3.0 \mathrm{mV}$ was reported earlier [34]. When all the results are examined, it is seen that ZP values aren't at the limit of flocculation. This shows the stability of all PLGA NPs prepared.

In surface-modified formulations with CS, the ZP of the NPs increased significantly to positive values. $\mathrm{ZP}$ was observed in the range of +77.1 to $+77.5 \mathrm{mV}$ and +75.0 to $+76.6 \mathrm{mV}$, respectively, in blank CS-coated PLGA NPs and CS-coated CLR-loaded PLGA NPs. This is a consequence of the amino groups present in this polysaccharide and suggests that the PLGA NPs were adequately coated by CS [15]. Besides the high stability promoted by this high ZP value, positive surface charges are attracted by the negatively charged cell membranes, promoting adhesion and retention of the system at the site of action and in the intestinal epithelium, as well as increasing the absorption of the nanometric system [35]. In addition, the presence of CS may decrease the absorption and interaction of NPs by phagocytes because this absorption occurs more frequently on hydrophobic and negatively charged surfaces [36].

\subsubsection{Assessment of Cryoprotectant Effect on Nanoparticles}

Figure 2 shows the effect of cryoprotectant addition on CLR-loaded PLGA NPs and CS-coated CLR-loaded PLGA NPs sizes. Freeze-drying (lyophilization) is a popular and preferred procedure for increasing the stability of various pharmaceutical products. Since NPs may increase in PS during freezing and drying steps, special agents must be added to the suspension before freezing to protect them. The most popular cryoprotectants for freeze-dried NPs are sugar derivatives, e.g., trehalose, sucrose, glucose, and mannitol [5]. In this study, trehalose was used at different concentrations and the PSs of NPs were measured after lyophilization to determine the optimum concentration of the cryoprotectant. Usually, the level of cryoprotectant used ranges from $0 \%$ to $50 \%$ by weight, which is solubilized directly in the NP suspension immediately prior to lyophilization. According to Figure 2, PSs were similar for trehalose concentrations added at $450 \mu \mathrm{L}$ and $600 \mu \mathrm{L}$ and are almost equal to fresh formulation. Both PLGA and CS-coated PLGA NP size was increased at low concentration of 
trehalose and therefore, $450 \mu \mathrm{L}$ trehalose solution was found to be adequate for keeping the PS constant after freeze-drying.
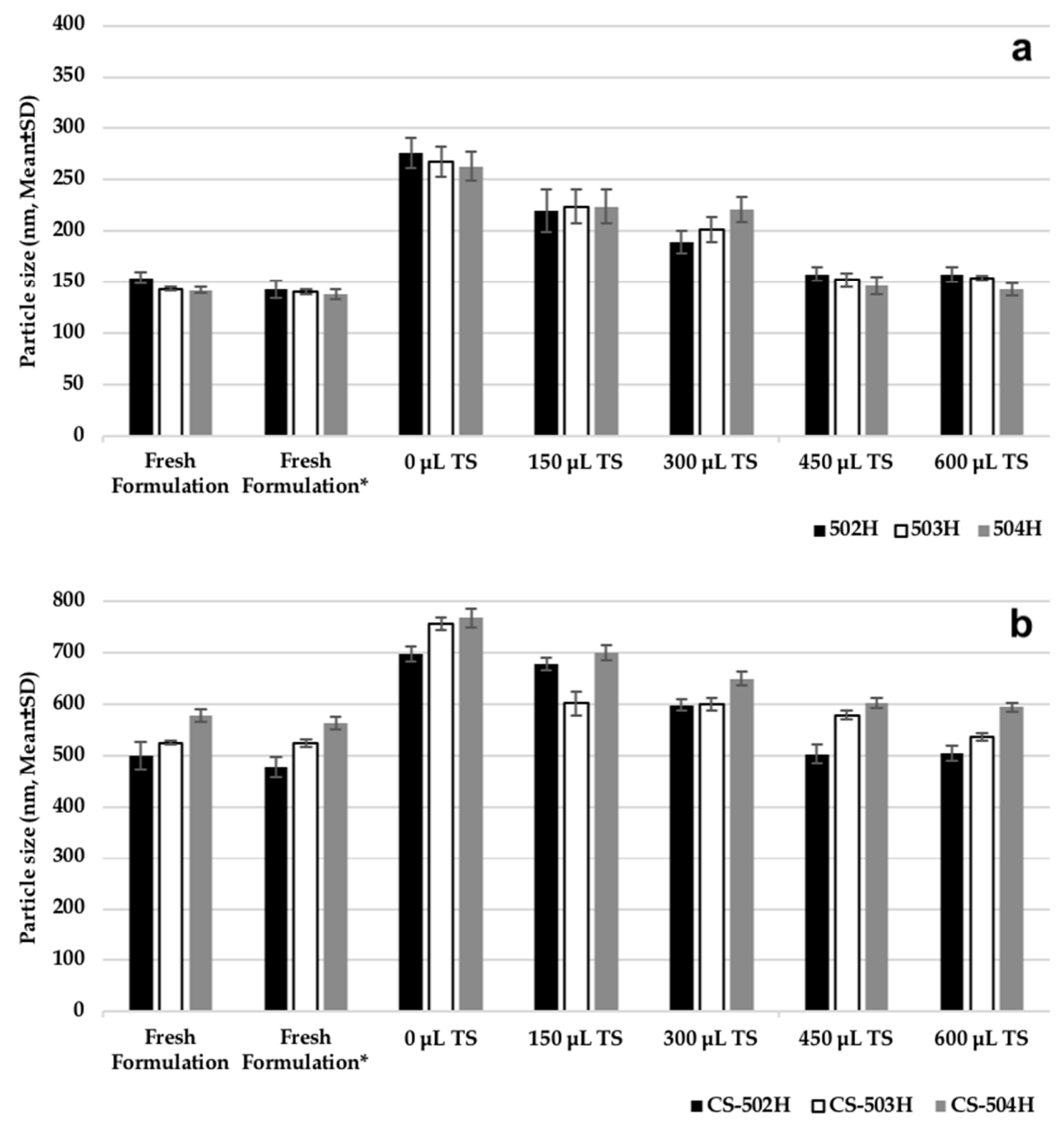

Figure 2. Effect of cryoprotectant on particle size of nanoparticles prepared; (a) PLGA nanoparticles (NPs), (b) chitosan-coated PLGA NPs. *: Fresh formulation after centrifugation and dispersing in $1 \mathrm{~mL}$ trehalose solution $(5 \% w / v)$.

\subsubsection{Evaluation of Gastrointestinal Stability of Nanoparticles}

For better understanding of in vitro release profiles, stabilities of both PLGA NPs and CS-coated PLGA NPs were analyzed at $37^{\circ} \mathrm{C}$ in different gastrointestinal media. Figure 3 shows NP sizes in $\mathrm{pH}$ 1.2 solution; intestinal fluid phosphate buffer solution ( $\mathrm{pH}$ 6.8); phosphate buffer solution ( $\mathrm{pH} 7.4$ ); and distilled water. NPs composed of hydrolytic degradable polymers are known to degrade over time. It was reported that temperature and $\mathrm{pH}$ have very significant effects on long-term stability of drugs [7]. After incubation for $24 \mathrm{~h}$ at $37^{\circ} \mathrm{C}$ in intestinal fluid phosphate buffer solution (pH 6.8), phosphate buffer solution ( $\mathrm{pH} 7.4$ ), and distilled water, average PS of NPs did not change significantly, when compared to the first PS measured for uncoated PLGA NPs. The results obtained indicate slow degradation of NPs in these medium at $37^{\circ} \mathrm{C}$, which also provides preliminary information for selection of dissolution medium. On the other hand, mean PS in pH 1.2 solution was determined to increase significantly in comparison to zero-time values. This indicates rapid degradation in the $\mathrm{pH}$ 1.2 solution. After incubation for $24 \mathrm{~h}$ at $37^{\circ} \mathrm{C}$ in $\mathrm{pH} 1.2$ solution; intestinal fluid phosphate buffer solution ( $\mathrm{pH}$ 6.8); phosphate buffer solution ( $\mathrm{pH} 7.4$ ); and distilled water, average PS of CS-coated 
PLGA NPs did not change significantly, when compared to the zero-time PS measured. The results obtained indicate slow degradation of CS coated PLGA NPs in all media at $37^{\circ} \mathrm{C}$, which also provides preliminary information for selection of dissolution medium. As a result, it can be said that CS coating slows down the degradation process and protects NPs $[5,7]$.
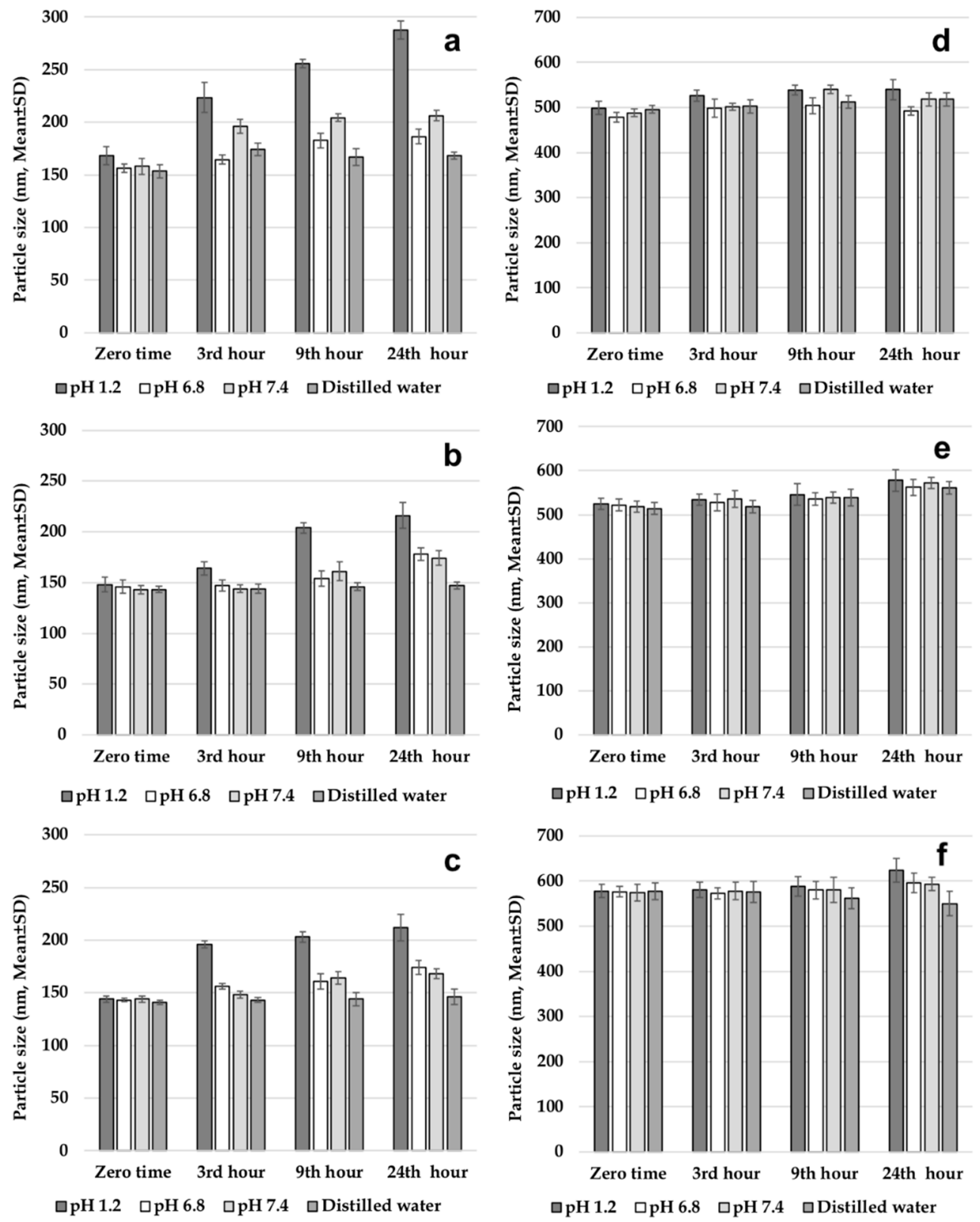

Figure 3. Gastrointestinal stability of nanoparticles, (a) $502 \mathrm{H},($ b) $503 \mathrm{H},(\mathbf{c}) 504 \mathrm{H},(d) \mathrm{CS}-502 \mathrm{H}$, (e) CS-503H, (f) CS-504H.

\subsubsection{High-Performance Liquid Chromatography (HPLC) Conditions}

The HPLC method used in the study was validated for precision, accuracy and linearity $[37,38]$. Linearity was at a concentration range of $20-70 \mu \mathrm{g} \cdot \mathrm{mL}^{-1}$. The method for CLR was precise due to RSD values of $<2 \%$ for repeatability and intermediate precision. Recovery of the method was satisfactory owing to $<2 \%$ RSD value. The CLR showed a linearity of $y=668.9238 x+2539.5397\left(r^{2}=0.999\right)$, and accuracy of $99.516 \% \pm 0.543 \%, 99.713 \% \pm 0.697 \%$, and $99.605 \% \pm 1.386 \%$ (mean $\% \pm$ SD) for 45 , 55 and $65 \mu \mathrm{g} \cdot \mathrm{mL}^{-1}$, respectively $(n=6)$. The limit of detection (LOD) was $0.0014 \mu \mathrm{g} \cdot \mathrm{mL}^{-1}$, while the 
limit of quantitation (LOQ) was $0.0042 \mu \mathrm{g} \cdot \mathrm{mL}^{-1}$. The proposed procedure can be used for routine, simultaneous, and concurrent determination of CLR [39].

\subsubsection{Entrapment Efficiency}

The corresponding data are shown in Table 2. Values of EE\% for PLGA NPs ranged between $74 \%$ and $85 \%$. The high values of encapsulation for PLGA NPs achieved are probably due to the lipophilic nature of the CLR, which presents low affinity to water phases and thus tends to migrate to the organic phase [21]. Another finding that draws attention to the results of $\mathrm{EE} \%$ is that the results of the EE\% were found to be as $502 \mathrm{H}>503 \mathrm{H}>504 \mathrm{H}$. So, PLGA NPs prepared with Resomer ${ }^{\circledR} \mathrm{RG}$ $502 \mathrm{H}$ had the highest EE\%, whereas the NPs prepared with Resomer ${ }^{\circledR}$ RG $504 \mathrm{H}$ had the lowest EE\% in PS results. This is explained in the literature by the loading of hydrophobic drugs to NPs being closely matched to the associated solid-state drug-polymer solubility, i.e., the ability of the polymeric matrix to keep the drug dispersed. This is briefly summarized as follows: the solid-state solubility of the drug in the polymer was increased with a decrease in $\mathrm{M}_{\mathrm{w}}[28,40]$. This theory supports the EE\% results we obtained in this study. The EE\% of CLR in CS coated-PLGA NPs ranged between $62 \%$ and $63 \%$. A decrease in EE\% was observed in CS-coated PLGA NPs compared with uncoated PLGA NPs. When the cause of this condition was investigated in the literature, similar results were obtained in CS-coated paclitaxel-loaded PLGA NPs [41]. This can be explained briefly, as a possible cause of CS hydrophilicity, which may prevent entrapment of the hydrophobic drug.

\subsubsection{Dissolution and Release Kinetic Evaluation}

We evaluated the amount of CLR released from developed PLGA NPs, CS-coated PLGA NPs, and CLR suspension as a function of time. In vitro dissolution profiles of the pure CLR, uncoated and CS-coated PLGA NP formulations prepared are presented in Figure 4. Twenty-four hour dissolution profiles are also presented in Figure $4 \mathrm{~b}$ to provide a more detailed view. The in vitro dissolution profiles of the uncoated and coated PLGA NPs showed a similar biphasic configuration, consisting of initial burst followed by a sustained release. The release of CLR from all NPs continued over $144 \mathrm{~h}$ while pure CLR exhibited a rapid release of $94.1 \% \pm 3.8 \%$ (mean $\pm \mathrm{SD}$ ) in $3 \mathrm{~h}$. The dissolution rates observed from $502 \mathrm{H}, 503 \mathrm{H}, 504 \mathrm{H}, \mathrm{CS}-502 \mathrm{H}, \mathrm{CS}-503 \mathrm{H}$ and CS-504H coded NP formulations after $144 \mathrm{~h}$ were $96.3 \% \pm 2.2 \%, 87.2 \% \pm 4.6 \%, 58.2 \% \pm 3.2 \%, 88.4 \% \pm 1.1 \%, 76.4 \% \pm 5.1 \%$, and $47.5 \% \pm 6.4 \%$, respectively, demonstrating extended release from all formulations, relative to pure CLR. Figure 4 shows that in the case of CS-coated PLGA NPs, the CLR release rate was slightly slower than that of the uncoated PLGA NPs. CLR released was primarily due to desorption and diffusion of the drug from the surface and the small pores on the surface of the NPs. In this case, the slower CLR release rate might be attributed to the variation in desorption and diffusion of drug because of CS coating on the PLGA NPs [42]. The release results indicate that the CS -NPs exhibited a CLR release pattern similar to the uncoated NPs, but with a slower CLR release rate.

When the results of the dissolution study were examined, a rapid release was observed up to $24 \mathrm{~h}$. Cumulative release rates with burst release at the 24th hour of $502 \mathrm{H}, 503 \mathrm{H}, 504 \mathrm{H}, \mathrm{CS}-502 \mathrm{H}, \mathrm{CS}-503 \mathrm{H}$ and CS-504H coded formulations were found as follows; $76.4 \% \pm 3.6 \%, 66.1 \% \pm 2.8 \%, 38.2 \% \pm 3.4 \%$, $54.6 \% \pm 4.2 \%, 48.8 \% \pm 2.8 \%$, and $31.4 \% \pm 2.4$, respectively. The rapid release of these formulations was finished at the end of the 24th hour and passed to their second phase, which was slow release. The most important factor that draws attention here is that the release rates in the first phase (burst effect) were found for uncoated formulation as $502 \mathrm{H}>503 \mathrm{H}>504 \mathrm{H}$ and for CS-coated formulation as CS-502H $>$ CS-503H > CS-504H and a similar result was observed at the end of $144 \mathrm{~h}$. There seems to be an inverse relationship between amount of release rate and PS. It was reported previously that large NPs degrade faster than small NPs. This is probably due to the increased accumulation of acidic products during polymer hydrolysis in large NPs where hydrolysis starts immediately in PLGA systems [7,43]. In this case, it can be said that the dissolution rates are indirectly influenced by $\mathrm{M}_{\mathrm{w}}$. This hypothesis is 
supported by the fact that the $504 \mathrm{H}$-coded formulation with small PS has the least dissolution rate and $502 \mathrm{H}$-coded formulation with largest PS has the highest dissolution rate.
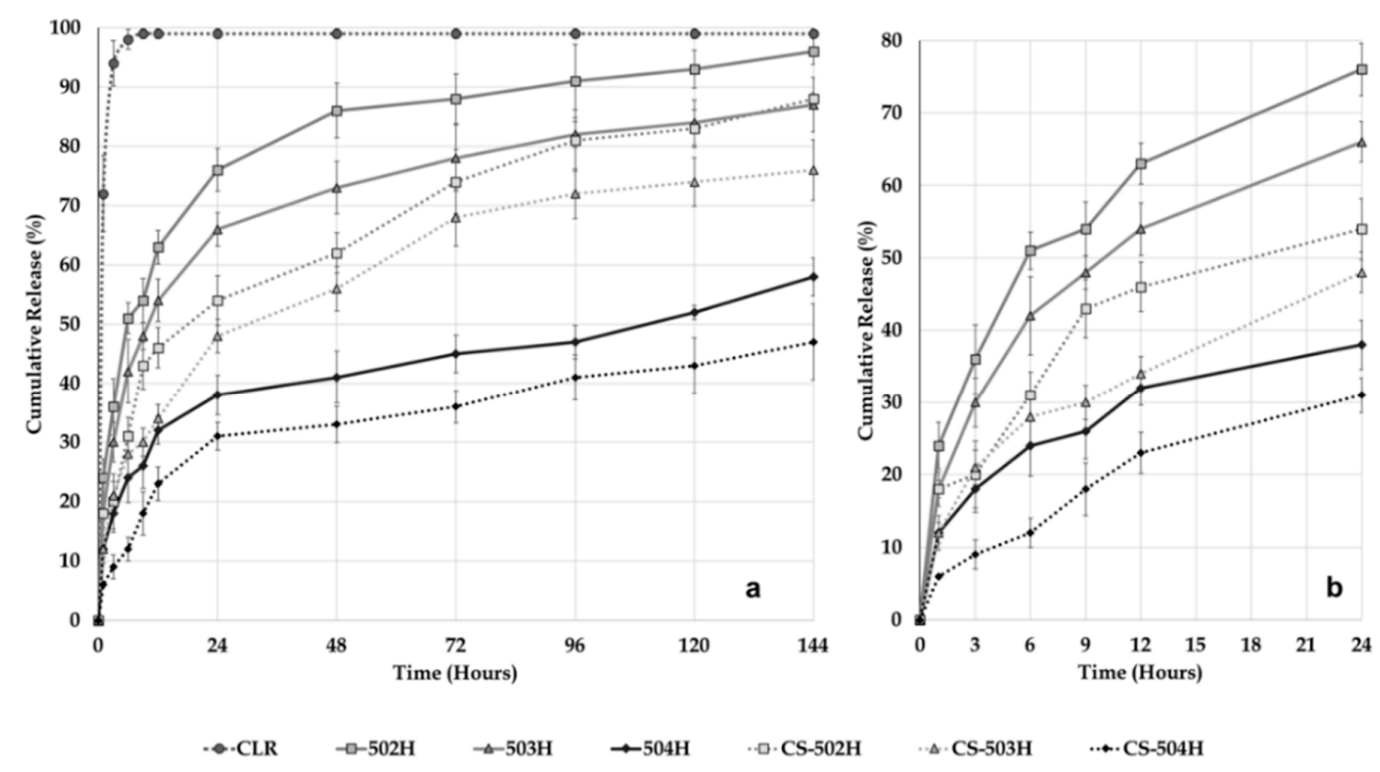

Figure 4. In vitro release of pure CLR, CLR from PLGA NPs and CS-coated PLGA NPs at $37{ }^{\circ} \mathrm{C}$ in intestinal fluid phosphate buffer $\mathrm{pH} 6.8$ supplemented with $1 \%$ Tween 80 . (a) 144 hours release profile, (b) 24 hours release profile.

Kinetic modeling of CLR release from NPs is shown in Tables 3-7. After obtaining the release profiles, data were transferred to the DDSolver program to determine the four most important and popular criteria: coefficient of determination (Rsqr, $R^{2}$, or COD), adjusted coefficient of determination (Rsqr_adj or $\mathrm{R}^{2}$ adjusted), Akaike information criterion (AIC), and model selection criterion (MSC). The highest $R^{2}, R^{2}$ adjusted, and MSC values and the lowest AIC values were used for evaluating Higuchi, Korsmeyer-Peppas, Baker-Lonsdale, Peppas-Sahlin and Weibull models [26]. In the investigation of drug release kinetics, it was seen that most of the studies were applied to the mathematical models for the total duration of the release [3,5,7]. This is known to be the right approach, but when new approaches are examined, the burst release kinetics of drugs and the total release kinetics can vary [44]. Therefore, in this study, a burst effect of $24 \mathrm{~h}$ was observed when the in vitro dissolution results were examined, and both the burst release kinetics and the $144 \mathrm{~h}$ kinetics were examined. Burst release leads to a high level of drug delivery at first and it is also important for the drug delivery system to provide a therapeutic concentration for effective treatment. Since the burst effect occurred in a very short time compared to the whole release time, most published results did not specifically investigate burst effect [45]. The $\mathrm{R}^{2}$ and $\mathrm{R}^{2}$ adjusted values for the Higuchi, Korsmeyer-Peppas, and Baker-Lonsdale models were smaller than other models for all NPs, which were relatively small. This suggests the drug release does not comply with Higuchi, Korsmeyer-Peppas, Baker-Lonsdale models. When the kinetics results of $24 \mathrm{~h}$ and $144 \mathrm{~h}$ were examined, the values of $\mathrm{R}^{2}, \mathrm{R}^{2}$ adjusted, MSC, and AIC were very similar for Peppas-Sahlin and Weibull models (Tables 6 and 7). In other words, higher correlation was observed in the Peppas-Sahlin model and Weibull model. Therefore, results of this study indicate that release of CLR from NPs is not predominantly driven by a solo mechanism, but a combined mechanism of Fickian (pure diffusion phenomenon) and non-Fickian release (due to the relaxation of the polymer chain between networks). When the literature is examined, similar results were encountered [46]. As seen in the results, the kinetic was not affected directly by $\mathrm{M}_{\mathrm{W}}$ or affected by the natural structure of the PLGA and CS. 
Table 3. Kinetic results for Higuchi Model.

\begin{tabular}{|c|c|c|c|c|c|c|c|c|c|c|c|c|c|}
\hline \multirow{3}{*}{ Model } & \multirow{3}{*}{$\begin{array}{l}\text { Evaluation } \\
\text { Criteria }\end{array}$} & \multicolumn{12}{|c|}{ Formulations } \\
\hline & & \multicolumn{6}{|c|}{24 Hours Kinetics } & \multicolumn{6}{|c|}{144 Hours Kinetics } \\
\hline & & $502 \mathrm{H}$ & $503 \mathrm{H}$ & $504 \mathrm{H}$ & $\mathrm{CS}-502 \mathrm{H}$ & CS-502H & CS-502H & $502 \mathrm{H}$ & $503 \mathrm{H}$ & $504 \mathrm{H}$ & CS-502H & CS-502H & CS-502H \\
\hline \multirow{4}{*}{ Higuchi } & $\mathbf{R}^{2}$ & 0.938 & 0.960 & 0.947 & 0.943 & 0.980 & 0.976 & 0.569 & 0.667 & 0.762 & 0.860 & 0.904 & 0.910 \\
\hline & $\mathbf{R}^{2}$ adjusted & 0.938 & 0.960 & 0.947 & 0.943 & 0.980 & 0.976 & 0.569 & 0.667 & 0.762 & 0.860 & 0.904 & 0.910 \\
\hline & AIC & 40.462 & 35.621 & 29.592 & 35.649 & 25.676 & 21.375 & 103.060 & 97.800 & 81.997 & 87.731 & 80.915 & 68.140 \\
\hline & MSC & 1.843 & 2.347 & 2.016 & 2.021 & 3.069 & 3.109 & 0.199 & 0.509 & 0.876 & 1.481 & 1.889 & 1.985 \\
\hline
\end{tabular}

Table 4. Kinetic results for Korsmeyer-Peppas Model.

\begin{tabular}{|c|c|c|c|c|c|c|c|c|c|c|c|c|c|}
\hline \multirow{3}{*}{ Model } & \multirow{3}{*}{$\begin{array}{l}\text { Evaluation } \\
\text { Criteria }\end{array}$} & \multicolumn{12}{|c|}{ Formulations } \\
\hline & & \multicolumn{6}{|c|}{24 Hours Kinetics } & \multicolumn{6}{|c|}{144 Hours Kinetics } \\
\hline & & $502 \mathrm{H}$ & $503 \mathrm{H}$ & $504 \mathrm{H}$ & CS-502H & CS-502H & $\mathrm{CS}-502 \mathrm{H}$ & $502 \mathrm{H}$ & $503 \mathrm{H}$ & $504 \mathrm{H}$ & CS-502H & CS-502H & $\mathrm{CS}-502 \mathrm{H}$ \\
\hline \multirow{4}{*}{ Korsmeyer-Peppas } & $\mathbf{R}^{2}$ & 0.993 & 0.990 & 0.994 & 0.969 & 0.994 & 0.982 & 0.982 & 0.982 & 0.991 & 0.992 & 0.994 & 0.982 \\
\hline & $\mathbf{R}^{2}$ adjusted & 0.991 & 0.988 & 0.993 & 0.962 & 0.993 & 0.978 & 0.957 & 0.955 & 0.980 & 0.983 & 0.985 & 0.956 \\
\hline & AIC & 27.293 & 27.790 & 16.539 & 33.475 & 18.853 & 21.587 & 77.498 & 75.749 & 54.040 & 64.710 & 60.683 & 61.474 \\
\hline & MSC & 3.725 & 3.466 & 3.881 & 2.331 & 4.043 & 3.079 & 2.329 & 2.347 & 3.205 & 3.399 & 3.575 & 2.540 \\
\hline
\end{tabular}

Table 5. Kinetic results for Baker-Lonsdale Model.

\begin{tabular}{|c|c|c|c|c|c|c|c|c|c|c|c|c|c|}
\hline \multirow{3}{*}{ Model } & \multirow{3}{*}{$\begin{array}{l}\text { Evaluation } \\
\text { Criteria }\end{array}$} & \multicolumn{12}{|c|}{ Formulations } \\
\hline & & \multicolumn{6}{|c|}{24 Hours Kinetics } & \multicolumn{6}{|c|}{144 Hours Kinetics } \\
\hline & & $502 \mathrm{H}$ & $503 \mathrm{H}$ & $504 \mathrm{H}$ & $\mathrm{CS}-502 \mathrm{H}$ & CS-502H & CS-502H & $502 \mathrm{H}$ & $503 \mathrm{H}$ & $504 \mathrm{H}$ & CS-502H & CS-502H & $\mathrm{CS}-502 \mathrm{H}$ \\
\hline \multirow{4}{*}{ Baker-Lonsdale } & $\mathbf{R}^{2}$ & 0.962 & 0.971 & 0.945 & 0.941 & 0.987 & 0.961 & 0.687 & 0.861 & 0.833 & 0.950 & 0.957 & 0.916 \\
\hline & $\mathbf{R}_{\text {adjusted }}^{2}$ & 0.962 & 0.971 & 0.945 & 0.941 & 0.987 & 0.961 & 0.687 & 0.861 & 0.833 & 0.950 & 0.957 & 0.916 \\
\hline & AIC & 37.014 & 33.383 & 29.906 & 35.903 & 22.566 & 24.810 & 99.208 & 87.319 & 77.743 & 75.423 & 71.306 & 67.328 \\
\hline & MSC & 2.336 & 2.667 & 1.971 & 1.984 & 3.513 & 2.619 & 0.520 & 1.383 & 1.230 & 2.507 & 2.690 & 2.052 \\
\hline
\end{tabular}


Table 6. Kinetic results for Peppas-Sahlin Model.

\begin{tabular}{|c|c|c|c|c|c|c|c|c|c|c|c|c|c|}
\hline \multirow{3}{*}{ Model } & \multirow{3}{*}{$\begin{array}{l}\text { Evaluation } \\
\text { Criteria }\end{array}$} & \multicolumn{12}{|c|}{ Formulations } \\
\hline & & \multicolumn{6}{|c|}{24 Hours Kinetics } & \multicolumn{6}{|c|}{144 Hours Kinetics } \\
\hline & & $502 \mathrm{H}$ & $503 \mathrm{H}$ & $504 \mathrm{H}$ & CS-502H & CS-502H & CS-502H & $502 \mathrm{H}$ & $503 \mathrm{H}$ & $504 \mathrm{H}$ & CS-502H & CS-502H & $\mathrm{CS}-502 \mathrm{H}$ \\
\hline \multirow{4}{*}{ Peppas-Sahlin } & $\mathbf{R}^{2}$ & 0.997 & 0.998 & 0.995 & 0.971 & 0.994 & 0.985 & 0.990 & 0.992 & 0.984 & 0.988 & 0.997 & 0.980 \\
\hline & $\mathbf{R}^{2}$ adjusted & 0.995 & 0.996 & 0.992 & 0.957 & 0.991 & 0.978 & 0.988 & 0.990 & 0.980 & 0.985 & 0.996 & 0.975 \\
\hline & AIC & 24.226 & 19.884 & 17.220 & 34.845 & 21.460 & 22.075 & 62.011 & 57.619 & 53.926 & 62.193 & 44.420 & 54.189 \\
\hline & MSC & 4.163 & 4.596 & 3.783 & 2.136 & 3.671 & 3.009 & 3.620 & 3.857 & 3.215 & 3.609 & 4.930 & 3.147 \\
\hline
\end{tabular}

Table 7. Kinetic results for Weibull Model.

\begin{tabular}{|c|c|c|c|c|c|c|c|c|c|c|c|c|c|}
\hline \multirow{3}{*}{ Model } & \multirow{3}{*}{$\begin{array}{l}\text { Evaluation } \\
\text { Criteria }\end{array}$} & \multicolumn{12}{|c|}{ Formulations } \\
\hline & & \multicolumn{6}{|c|}{24 Hours Kinetics } & \multicolumn{6}{|c|}{144 Hours Kinetics } \\
\hline & & $502 \mathrm{H}$ & $503 \mathrm{H}$ & $504 \mathrm{H}$ & $\mathrm{CS}-502 \mathrm{H}$ & $\mathrm{CS}-502 \mathrm{H}$ & CS-502H & $502 \mathrm{H}$ & $503 \mathrm{H}$ & $504 \mathrm{H}$ & $\mathrm{CS}-502 \mathrm{H}$ & $\mathrm{CS}-502 \mathrm{H}$ & CS-502H \\
\hline \multirow{3}{*}{ Weibull } & $\mathbf{R}^{2}$ adjusted & 0.989 & 0.998 & 0.989 & 0.944 & 0.982 & 0.956 & 0.996 & 0.996 & 0.985 & 0.984 & 0.994 & 0.972 \\
\hline & AIC & 29.294 & 15.444 & 19.732 & 36.659 & 25.936 & 26.950 & 48.613 & 47.099 & 50.713 & 63.687 & 49.256 & 55.717 \\
\hline & MSC & 3.439 & 5.230 & 3.424 & 1.876 & 3.031 & 2.313 & 4.736 & 4.734 & 3.483 & 3.485 & 4.527 & 3.020 \\
\hline
\end{tabular}




\subsection{Solid State Characterization of Nanoparticles}

\subsubsection{Thermal (DSC) Analysis}

DSC curves/thermograms of intact CLR, blank NPs and CLR-loaded NPs are demonstrated in Figure 5. CLR (Figure 5a) presented a melting endothermic peak at $228.84{ }^{\circ} \mathrm{C}$. The result was found to be appropriate compared to the literature [24]. No clear peak presented (Figure $5 \mathrm{~h}-\mathrm{m}$ ) in the thermograms of the prepared uncoated and CS-coated PLGA NPs due to any possible decrease in the drug crystallinity and/or solvation of the drug in the melted carrier and/or heat-induced interaction between drug and polymer [47]. This disappearance of melting peaks of CLR from the NP formulation thermograms indicated that CLR was likely encapsulated in the amorphous state and molecularly dispersed in the polymeric structure $[48,49]$. The thermograms demonstrated that there was no interaction between the CLR and the polymers. These data are important because the presence of a drug in molecular dispersion form helps in its sustained release property [50].

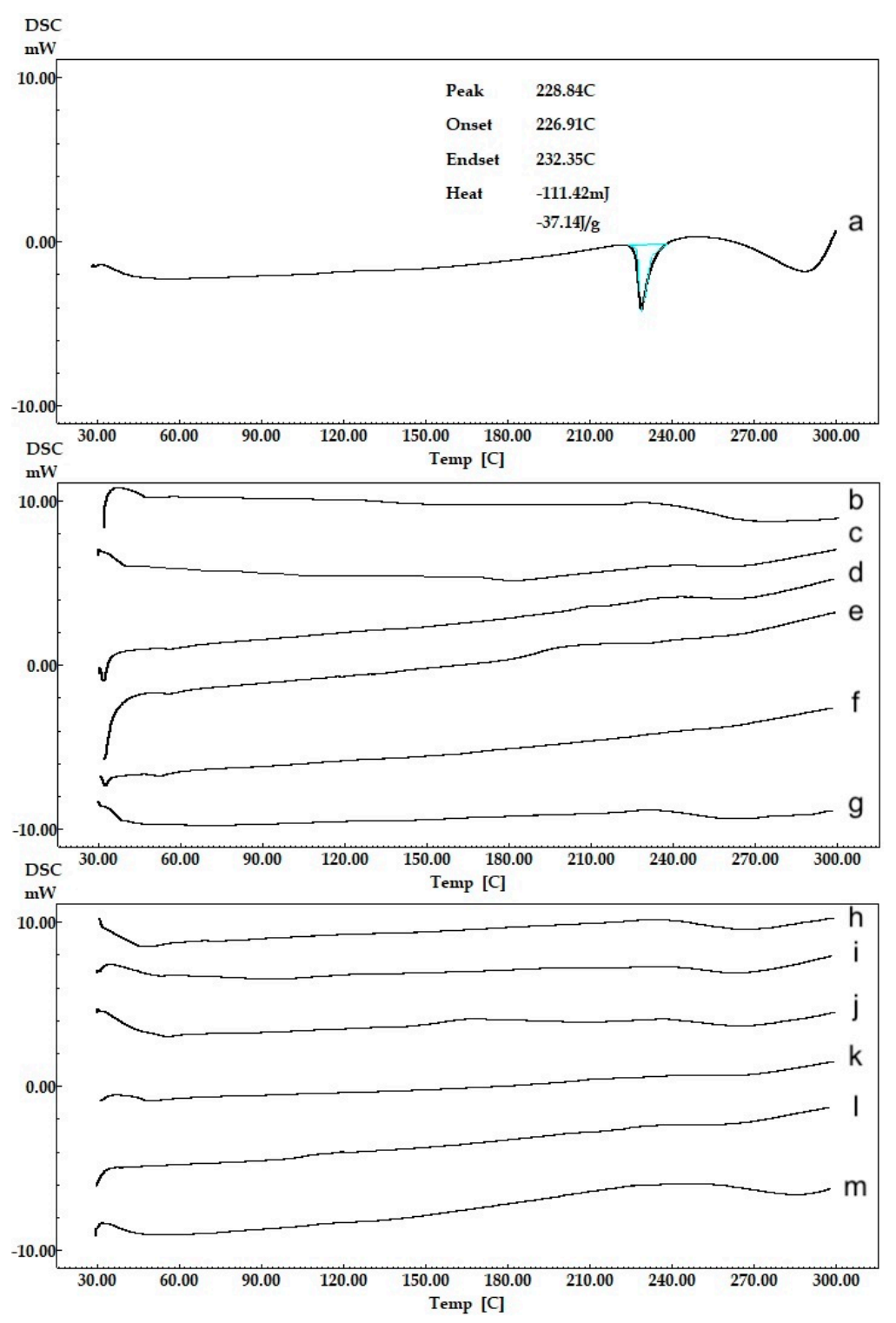

Figure 5. Thermal (DSC) analysis curves of CLR and NPs, (a) CLR, (b) 502H-Blank, (c) 503H-Blank, (d) 504H-Blank, (e) CS-502H-Blank, (f) CS-503H-Blank, (g) CS-504H-Blank, (h) 502H, (i) 503H, (j) 504H, (k) CS-502H, (1) CS-503H, (m) CS-504H. 


\subsubsection{FT-IR Analysis}

FT-IR spectrum of CLR and formulations are given in Figure 6. FT-IR spectrum of CLR (Figure 6a) showed peak for $\mathrm{C}-\mathrm{H}$ stretching vibration at $2978 \mathrm{~cm}^{-1}$; peak of $-\mathrm{O}-\mathrm{C}=\mathrm{O}$ stretching vibration in lactone ring and $-\mathrm{C}=\mathrm{O}$ stretching ketone group at $1732 \mathrm{~cm}^{-1}$ and around $1600 \mathrm{~cm}^{-1}$, respectively, peaks at $1166 \mathrm{~cm}^{-1}$ and $1010 \mathrm{~cm}^{-1}$ refer to -O-ether functional band. The FT-IR spectrum of CLR was consistent with the literature [24]. Resomer ${ }^{\circledR}$ RG 502 H, Resomer ${ }^{\circledR}$ RG 503 H, and Resomer ${ }^{\circledR}$ RG 502 H are PLGA polymers having the same chemical structures but with different $\mathrm{M}_{\mathrm{w}}$. Carbonyl groups $(\mathrm{C}=\mathrm{O})$ observed between 1749-1755 $\mathrm{cm}^{-1}$ with intense bands were attributed to stretching vibration present in both monomers, while medium density bands between 1300 and $1100 \mathrm{~cm}^{-1}$ were, respectively, attributed to asymmetric and symmetric $\mathrm{C}-\mathrm{C}(=\mathrm{O})-\mathrm{O}$ stretches in blank formulation spectrum (Figure $6 \mathrm{~b}-\mathrm{g})[5,7]$. FT-IR spectrum of CS-coated blank formulation (Figure 6e-g) showed characteristic absorption bands around $3750-2500 \mathrm{~cm}^{-1}$, which represent $-\mathrm{OH},-\mathrm{CH}_{2}$, and $-\mathrm{CH}_{3}$ aliphatic groups, and bands at around $1400-1500 \mathrm{~cm}^{-1}$ that represent -NH group bending vibration and vibrations of the -OH group of the primary alcohol, respectively. Since the PLGA peaks are overly dominant, they have reduced the selectivity of the CS peaks, but in some regions the peaks of CS suppressed the peak peaks of the PLGA. This can be considered as an indicator of CS coating [49]. The FT-IR spectrum obtained for CLR loaded all NPs that displayed the typical bands of drug and PLGA; a possible new carbonyl stretching band at higher wave number (due to potential interactions between CLR and all type of PLGA) was masked by the broad carbonyl stretching band at $1753-1751 \mathrm{~cm}^{-1}$ (also seen in the all blank formulation spectrum). Similar results were observed with the flurbiprofen-loaded Resomer ${ }^{\circledR}$ RG 756

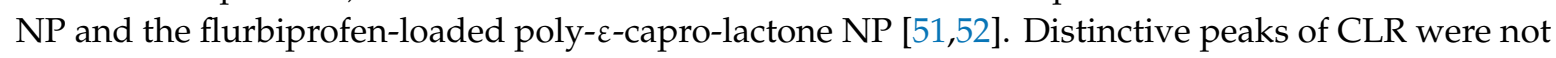
seen in the spectra of all CLR-loaded NP formulations indicating the molecular dispersion of CLR in the polymeric matrices, which was supported by the DSC results [49]. The absence of CLR distinctive peaks confirmed encapsulation of drug within the polymeric structure. 


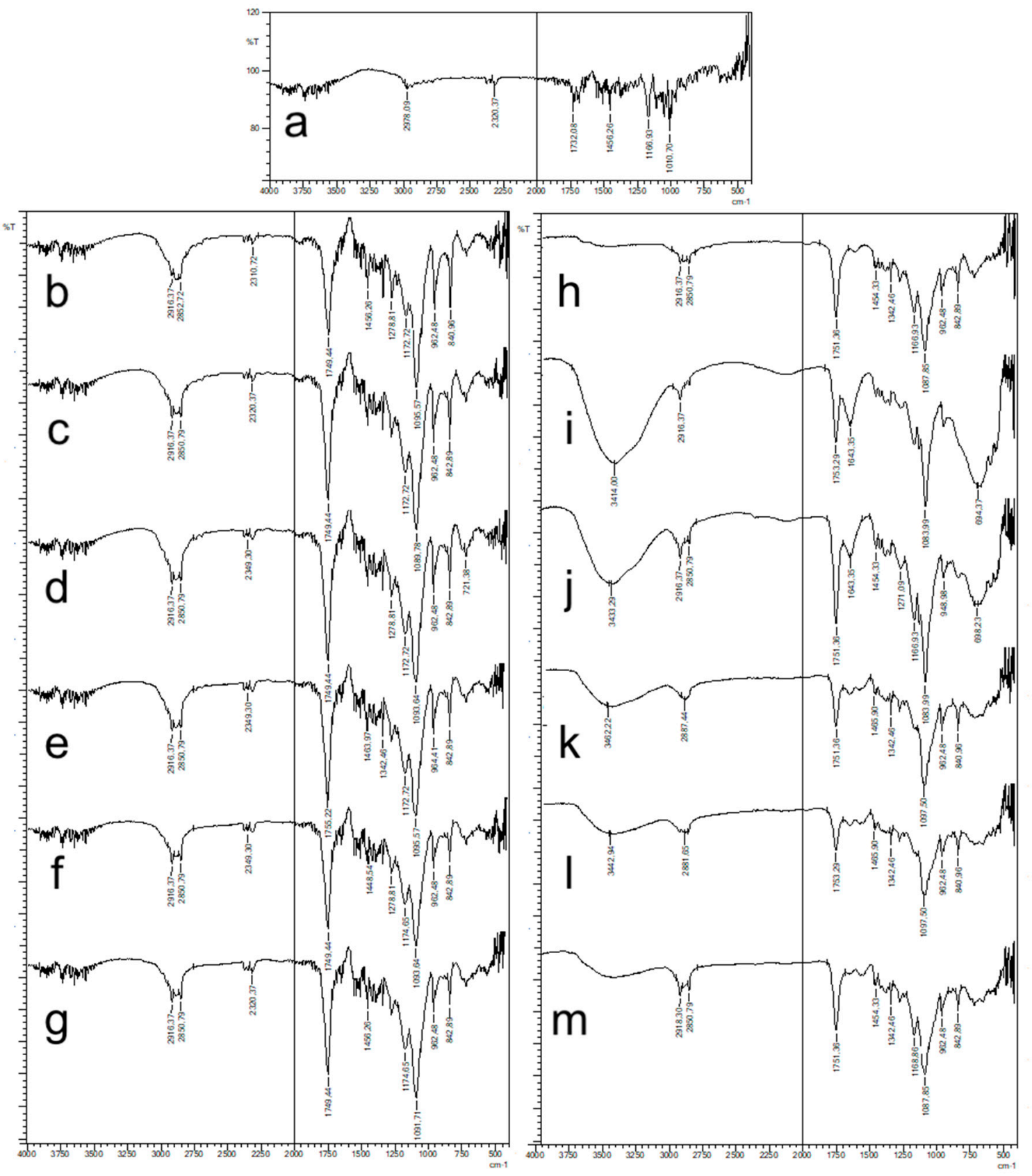

Figure 6. FT-IR spectrum of CLR and NPs, (a) CLR, (b) 502H-Blank, (c) 503H-Blank, (d) 504H-Blank, (e) CS-502H-Blank, (f) CS-503H-Blank, (g) CS-504H-Blank, (h) 502H, (i) 503H, (j) 504H, (k) CS-502H, (1) $\mathrm{CS}-503 \mathrm{H},(\mathbf{m}) \mathrm{CS}-504 \mathrm{H}$.

\subsection{3. ${ }^{1} \mathrm{H}-\mathrm{NMR}$ Analysis}

In the ${ }^{1} \mathrm{H}-\mathrm{NMR}$ analysis, the active substance and polymer signals can be better observed than in the FT-IR analysis as the materials are dissolved in the deutero-solvent. The ${ }^{1} \mathrm{H}-\mathrm{NMR}$ spectra of CLR and formulation are shown in Figure 7. The ${ }^{1} \mathrm{H}-\mathrm{NMR}$ spectrum of CLR (Figure 7a) shows a similarity to the literature [53]. Characteristic ${ }^{1} \mathrm{H}-\mathrm{NMR}$ signals for CLR are dense signals of $1-5 \mathrm{ppm}$. PLGA contains two types of structural units: the most intense signals of $\mathrm{CH}(5.1 \mathrm{ppm})$ and $\mathrm{CH}_{3}(1.4 \mathrm{ppm})$ from lactic acid and $\mathrm{CH}_{2}(4.8 \mathrm{ppm})$ from glycolic acid. The $\mathrm{CH}_{2}$ hydrogens were diastrophic and divided into two, ending in two pairs of peaks that were assigned for both protons. Higher $\mathrm{CH}_{2}, \mathrm{CH}_{3}$, and $\mathrm{CH}$ signals in the copolymer caused those peaks to expand. When the ${ }^{1} \mathrm{H}-\mathrm{NMR}$ spectrum of both blank and CLR-loaded NPs is examined, specific peaks of the PLGA polymer are observed in Figure $7 \mathrm{~b}-\mathrm{m}$. 
Signals at $4.9 \mathrm{ppm}$ are for D-glucosamine unit, signals at $4.7 \mathrm{ppm}$ for N-acetyl-D-glucosamine, signals at $3.2 \mathrm{ppm}$ and $2.1 \mathrm{ppm}$ for $-\mathrm{CH} 3$ are specific signals for chitosan [54]. When the ${ }^{1} \mathrm{H}-\mathrm{NMR}$ spectrum of both blank and CLR-loaded NPs is examined, specific peaks of the CS are observed in Figure 7e-m. Figure $7 \mathrm{~h}-\mathrm{m}$ shows specific ${ }^{1} \mathrm{H}-\mathrm{NMR}$ signals of CLR in both PLGA NPs and CS-coated PLGA NPs. This indicates that the CLR has been successfully loaded into the formulations [55].

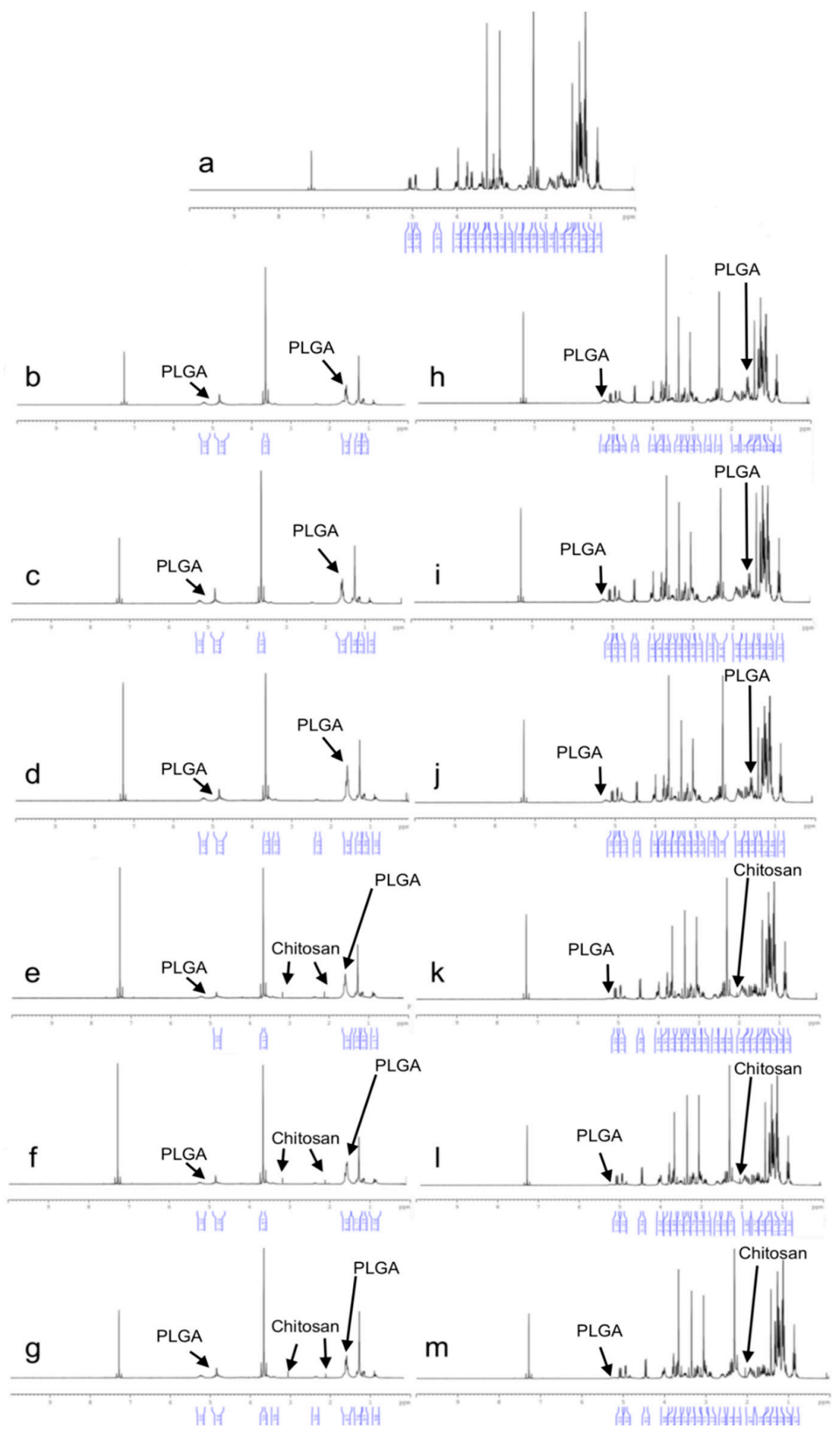

Figure 7. ${ }^{1} \mathrm{H}-\mathrm{NMR}$ spectrum of CLR and NPs, (a) CLR, (b) 502H-Blank, (c) 503H-Blank, (d) 504H-Blank, (e) CS-502H-Blank, (f) CS-503H-Blank, (g) CS-504H-Blank, (h) 502H, (i) 503H, (j) 504H, (k) CS-502H, (l) $\mathrm{CS}-503 \mathrm{H},(\mathbf{m}) \mathrm{CS}-504 \mathrm{H}$. 


\subsection{Antimicrobial Activity Test Results}

The antimicrobial activities of prepared compounds were tested on microorganisms including Staphylococcus aureus (ATCC 25923), Enterococcus faecalis (ATCC 29212), Listeria monocytogenes (ATCC 1911), and Klebsiella pneumoniae (ATCC 700603). The results are given in Table 8.

Table 8. Antimicrobial test results.

\begin{tabular}{lcccc}
\hline Formulation Codes & $\begin{array}{c}\text { Staphylococcus } \\
\text { aureus (ATCC } \\
\text { 25923) }\end{array}$ & $\begin{array}{c}\text { Enterococcus } \\
\text { faecalis (ATCC } \\
\text { 29212) }\end{array}$ & $\begin{array}{c}\text { Listeria } \\
\text { monocytogenes } \\
\text { (ATCC 1911) }\end{array}$ & $\begin{array}{c}\text { Klebsiella } \\
\text { pneumoniae } \\
\text { (ATCC 700603) }\end{array}$ \\
\hline CS-502H & $62.50 \mu \mathrm{g} \cdot \mathrm{mL}^{-1}$ & $250.00 \mu \mathrm{g} \cdot \mathrm{mL}^{-1}$ & $31.25 \mu \mathrm{g} \cdot \mathrm{mL}^{-1}$ & $62.50 \mu \mathrm{g} \cdot \mathrm{mL}^{-1}$ \\
\hline $502 \mathrm{H}$ & $62.50 \mu \mathrm{g} \cdot \mathrm{mL}^{-1}$ & $250.00 \mu \mathrm{g} \cdot \mathrm{mL}^{-1}$ & $31.25 \mu \mathrm{g} \cdot \mathrm{mL}^{-1}$ & $31.25 \mu \mathrm{g} \cdot \mathrm{mL}^{-1}$ \\
\hline CS-503H & $62.50 \mu \mathrm{g} \cdot \mathrm{mL}^{-1}$ & $250.00 \mu \mathrm{g} \cdot \mathrm{mL}^{-1}$ & $62.50 \mu \mathrm{g} \cdot \mathrm{mL}^{-1}$ & $31.25 \mu \mathrm{g} \cdot \mathrm{mL}^{-1}$ \\
\hline $503 \mathrm{H}$ & $31.25 \mu \mathrm{g} \cdot \mathrm{mL}^{-1}$ & $250.00 \mu \mathrm{g} \cdot \mathrm{mL}^{-1}$ & $62.50 \mu \mathrm{g} \cdot \mathrm{mL}^{-1}$ & $31.25 \mu \mathrm{g} \cdot \mathrm{mL}^{-1}$ \\
\hline CS-504H & $31.25 \mu \mathrm{g} \cdot \mathrm{mL}^{-1}$ & $250.00 \mu \mathrm{g} \cdot \mathrm{mL}^{-1}$ & $62.50 \mu \mathrm{g} \cdot \mathrm{mL}^{-1}$ & $31.25 \mu \mathrm{g} \cdot \mathrm{mL}^{-1}$ \\
\hline $504 \mathrm{H}$ & $31.25 \mu \mathrm{g} \cdot \mathrm{mL}^{-1}$ & $250.00 \mu \mathrm{g} \cdot \mathrm{mL}^{-1}$ & $62.50 \mu \mathrm{g} \cdot \mathrm{mL}^{-1}$ & $62.50 \mu \mathrm{g} \cdot \mathrm{mL}^{-1}$ \\
\hline CLR & $125.00 \mu \mathrm{g} \cdot \mathrm{mL}^{-1}$ & $250.00 \mu \mathrm{g} \cdot \mathrm{mL}^{-1}$ & $125.00 \mu \mathrm{g} \cdot \mathrm{mL}^{-1}$ & $62.50 \mu \mathrm{g} \cdot \mathrm{mL}^{-1}$ \\
\hline Control (Chloramphenicol) & $7.81 \mu \mathrm{g} \cdot \mathrm{mL}^{-1}$ & $15.625 \mu \mathrm{g} \cdot \mathrm{mL}^{-1}$ & $15.625 \mu \mathrm{g} \cdot \mathrm{mL}^{-1}$ & $7.81 \mu \mathrm{g} \cdot \mathrm{mL}^{-1}$ \\
\hline
\end{tabular}

According to the antibacterial activity test results, obtained from minimum inhibitory concentration tests (MIC), many of the compounds were found to be active against the identified microorganisms compared to control. All formulations exhibited remarkable antibacterial activity, especially on Staphylococcus aureus (ATCC 25923), Listeria monocytogenes (ATCC 1911), and Klebsiella pneumoniae (ATCC 700603). 503H, 504H, and CS-504H showed significant activity compared to standard drug (Chloramphenicol) and CLR against Staphylococcus aureus (ATCC 25923). Only one of four microorganisms, Enterococcus faecalis (ATCC 29212), has not been found to be susceptible for these formulations.

Antimicrobial effects can be discussed in terms of pharmaceutical technology as follows. In this study, PLGA with three different $\mathrm{M}_{\mathrm{w}}$ and CS were used. When PSs were examined, the highest PS was found in the CS-504H-coded formulation. Compared to non-CS-coated formulations, the increase in PS was most observed in the CS-504 H-coded formulation. This is proof that CS is more present in the CS $504 \mathrm{H}$-coded formulation than CS-502H and CS 503H. When the literature is examined, there is a direct correlation between the $\mathrm{M}_{\mathrm{w}}$ of chitosan and the antimicrobial effect. Many studies in the literature have shown that as the $M_{w}$ of chitosan increases, its antimicrobial activity increases [56,57]. When the results were discussed from a different perspective, according to these literature, the presence of more CS in CS-504H increased the antimicrobial efficacy on Staphylococcus aureus. The other two formulations with high antimicrobial effect on Staphylococcus aureus are formulations coded with $503 \mathrm{H}$ and $504 \mathrm{H}$. When the literature is examined, it has been observed in many studies that the antimicrobial effect increases when the PS decreases [58,59]. When the results of PS are examined, the two formulations having the lowest PS were $503 \mathrm{H}$ and $504 \mathrm{H}$ coded formulations. It can be said that the low PS increased the antimicrobial effect on Staphylococcus aureus. There have been studies in the literature with CLR $[24,60]$. When these studies were examined, the MIC value of CLR against Staphylococcus aureus was found to be $0.5 \mu \mathrm{g} . \mathrm{mL}^{-1}$ and $12.0 \mu \mathrm{g} \cdot \mathrm{mL}^{-1}$. In this study, the MIC value of the CLR against Staphylococcus aureus was observed to be $125 \mu \mathrm{g} . \mathrm{mL}^{-1}$. While the bacterial chain used in our study was ATCC 25923 for Staphylococcus aureus, the bacterial chains in other studies were ATCC 29213 and MTCC 86 for Staphylococcus aureus. These are two different strains (ATCC 29213 and MTCC86) of Staphylococcus aureus. The same species of bacteria with different strain designations codes have different sensitivity to antimicrobial drugs [24]. This reason explains the differences in the literature with the results we obtained. 
As a result, all the formulations we prepared have increased antimicrobial effect compared to CLR. Due to the fact that free drug and NPs were investigated using the same concentration of CLR, the improvement in antimicrobial effect activity could be due to better penetration of the NPs into bacterial cells and better delivery of CLR to its site of action [61]. NPs are capable of being endocytosed by phagocytic cells and releasing the drug into those cells [62]. The CLR-loaded NPs could be suitable for delivery of CLR to phagocytic cells to achieve better treatment of infection compared with treatment using free CLR. This indicates that the newly designed antibiotic-releasing NPs may be appropriate for antimicrobial treatment.

\section{Conclusions}

In this study, nanoparticles were prepared with three different $\mathrm{M}_{\mathrm{w}}$ of PLGA and chitosan. We have successfully formulated clarithromycin-loaded nanoparticles by nanoprecipitation technique. Detailed characterizations were made to all formulations and obtained results showed that the $M_{w}$ of PLGA and chitosan modification exerted significant influence on the nanoparticle properties. The particle size of the prepared nanoparticles was in the range of 178 to $578 \mathrm{~nm}$ and it was affected by the $M_{w}$ and chitosan coating. In surface-modified formulations with chitosan, the zeta potential of the nanoparticles increased significantly to positive values. The entrapment efficiency results of formulations intended for oral use are highly acceptable. Entrapment efficiency varied from $62 \%$ to $85 \%$, depending upon the $\mathrm{M}_{\mathrm{w}}$ and chitosan coating. In vitro release studies of clarithromycin-loaded nanoparticles showed an extended release up to $144 \mathrm{~h}$. Peppas-Sahlin and Weibull kinetic model was found to fit best for clarithromycin release from nanoparticles. Solid-state characterization by DSC, FT-IR, and ${ }^{1} \mathrm{H}-\mathrm{NMR}$ has proven successful in the production of nanoparticles. The $503 \mathrm{H}, 504 \mathrm{H}$ and CS-504H coded formulations exhibited remarkable antibacterial activity, especially on Staphylococcus aureus. At least in terms of some formulations, improved pharmacodynamic effects were also obtained from antibacterial activity studies and it could be concluded that clarithromycin-loaded nanoparticles seem to be a promising delivery system for the oral application.

Author Contributions: Conceptualization, A.A.Ö.; method, A.A.Ö., E.Y., and M.G.Ö.; investigation, formulation, characterization, release, in-vitro work etc., A.A.Ö. and E.Y.; antimicrobial activity test, M.G.Ö.; writing-original draft, A.A.Ö.; review and editing and results interpretation, A.A.Ö., E.Y., and M.G.Ö.; supervision, A.A.Ö.; project administration, A.A.Ö., E.Y., and M.G.Ö.

Funding: This research work was supported by a grant from the Anadolu University Scientific Research Project Foundation (Project number 1806S238).

Acknowledgments: The authors would like to thank SANOVEL (Istanbul, Turkey) for providing a gift sample of clarithromycin. DOPNALAB Faculty of Pharmacy is acknowledged for FT-IR and ${ }^{1} \mathrm{H}-\mathrm{NMR}$ analysis facilities. The authors would also like to thank to corresponding author father' A. Nurol Öztürk for providing DSC cells.

Conflicts of Interest: The authors declare no conflict of interest.

\section{References}

1. Zakeri-Milani, P.; Islambulchilar, Z.; Majidpour, F.; Jannatabadi, E.; Lotfipour, F.; Valizadeh, H. A study on enhanced intestinal permeability of clarithromycin nanoparticles. Braz. J. Pharm. Sci. 2014, 50, 121-129. [CrossRef]

2. Rizvi, S.A.A.; Saleh, A.M. Applications of nanoparticle systems in drug delivery technology. Saudi. Pharm. J. 2018, 26, 64-70. [CrossRef] [PubMed]

3. Öztürk, A.A.; Yenilmez, E.; Şenel, B.; Arslan, R.; Yazan, Y. Dexketoprofen trometamol-loaded Kollidon ${ }^{\circledR}$ SR and Eudragit ${ }^{\circledR}$ RS 100 polymeric nanoparticles: Formulation and in vitro-in vivo evaluation. Lat. Am. J. Pharm. 2017, 36, 2153-2165.

4. Bamrungsap, S.; Zhao, Z.; Chen, T.; Wang, L.; Li, C.; Fu, T.; Tan, W. A Focus on nanoparticles as a drug delivery system. Nanomedicine 2012, 7, 1253-1271. [CrossRef] [PubMed] 
5. Öztürk, A.A.; Martin-Banderas, L.; Cayero-Otero, M.D.; Yenilmez, E.; Şenel, B.; Yazan, Y. Dexketoprofen trometamol-loaded Poly-Lactic-co-Glycolic Acid (PLGA) nanoparticles: Preparation, in vitro characterization and cyctotoxity. Trop. J. Pharm. Res. 2019, 18,1-11. [CrossRef]

6. Makadia, H.K.; Siegel, S.J. Poly lactic-co-glycolic acid (PLGA) as biodegradable controlled drug delivery carrier. Polymers 2011, 3, 1377-1397. [CrossRef]

7. Öztürk, A.A.; Martin-Banderas, L.; Cayero-Otero, M.D.; Yenilmez, E.; Yazan, Y. New approach to hypertension treatment: Carvedilol-loaded plga nanoparticles, preparation, in vitro characterization and gastrointestinal stability. Lat. Am. J. Pharm. 2018, 37, 1730-1741.

8. Sharma, A.; Sharma, S.; Khuller, G.K. Lectin-functionalized poly (lactide-co-glycolide) nanoparticles as oral/aerosolized antitubercular drug carriers for treatment of tuberculosis. J. Antimicrob. Chemother. 2004, 54, 761-766. [CrossRef]

9. Pandey, R.; Ahmad, Z.; Sharma, S.; Khuller, G.K. Nano-encapsulation of azole antifungals: Potential applications to improve oral drug delivery. Int. J. Pharm. 2005, 301, 268-276. [CrossRef]

10. Malinovskaya, Y.; Melnikov, P.; Baklaushev, V.; Gabashvili, A.; Osipova, N.; Mantrov, S.; Ermolenko, Y.; Maksimenko, O.; Gorshkova, M.; Balabanyan, V.; et al. Delivery of doxorubicin-loaded PLGA nanoparticles into U87 human glioblastoma cells. Int. J. Pharm. 2017, 524, 77-90. [CrossRef]

11. Öztürk, A.A.; Kırımlığlu, G.Y. Preparation and in vitro of characterization lamivudine loaded nanoparticles prepared by acid or ester terminated PLGA for effective oral antiretroviral therapy. J. Res. Pharm. 2019, 23, 897-913.

12. Hrkach, J.; Von-Hoff, D.; Mukkaram-Ali, M.; Andrianova, E.; Auer, J.; Campbell, T.; De Witt, D.; Figa, M.; Figueiredo, M.; Horhota, A.; et al. Preclinical development and clinical translation of a PSMA-targeted docetaxel nanoparticle with a differentiated pharmacological profile. Sci. Transl. Med. 2012, 4, 128 ra39. [CrossRef] [PubMed]

13. Madani, F.; Esnaashari, S.S.; Mujokoro, B.; Dorkoosh, F.; Khosravani, M.; Adabi, M. Investigation of Effective Parameters on Size of Paclitaxel Loaded PLGA Nanoparticles. Adv. Pharm. Bull. 2018, 8, 77-84. [CrossRef] [PubMed]

14. Prashanth, K.V.H.; Tharanathan, R.N. Chitin/chitosan: Modifications and their unlimited application potential. Trends. Food Sci. Technol. 2007, 18, 117-131. [CrossRef]

15. de Lima, I.A.; Khalil, N.M.; Tominaga, T.T.; Lechanteur, A.; Sarmento, B.; Mainardes, R.M. Mucoadhesive chitosan-coated PLGA nanoparticles for oral delivery of ferulic acid. Artif. Cells Nanomed. B 2018, 46, 993-1002. [CrossRef] [PubMed]

16. Van Nuffel, A.M.; Sukhatme, V.; Pantziarka, P.; Meheus, L.; Sukhatme, V.P.; Bouche, G. Repurposing drugs in oncology (ReDO)-clarithromycin as an anti-cancer agent. E Cancer. Med. Sci. 2015, 9, 1-26. [CrossRef] [PubMed]

17. Lebel, M. Pharmacokinetic properties of clarithromycin: A comparison with erythromycin and azithromycin. Can. J. Infect. Dis. 1993, 4, 148-152. [CrossRef] [PubMed]

18. Valizadeh, H.; Mohammadi, G.; Ehyaei, R.; Milani, M.; Azhdarzadeh, M.; Zakeri-Milani, P.; Lotfipour, F. Antibacterial activity of clarithromycin loaded PLGA nanoparticles. Pharmazie 2012, 67, 63-68. [PubMed]

19. Alenezi, A.; Naito, Y.; Terukina, T.; Prananingrum, W.; Jinno, Y.; Tagami, T.; Ozeki, T.; Galli, S.; Jimbo, R. Controlled release of clarithromycin from PLGA microspheres enhances bone regeneration in rabbit calvaria defects. J. Biomed. Mater. Res. Part. B 2018, 106B, 201-208. [CrossRef]

20. Jain, S.K.; Haider, T.; Kumar, A.; Jain, A. Lectin-Conjugated Clarithromycin and Acetohydroxamic Acid-Loaded PLGA Nanoparticles: A Novel Approach for Effective Treatment of H. pylori. AAPS Pharm. Sci. Tech. 2016, 17, 1131-1140. [CrossRef]

21. Duran-Lobato, M.; Martin-Banderas, L.; Goncalves, L.M.D.; Fernandez-Arevalo, M.; Almeida, A.J. Comparative study of chitosan-and peg-coated lipid and plga nanoparticles as oral delivery systems for cannabinoids. J. Nanopart. Res. 2015, 61, 1-17. [CrossRef]

22. Khan, N.; Ameeduzzafar; Khanna, K.; Bhatnagar, A.; Ahmad, F.J.; Alia, A. Chitosan coated PLGA nanoparticles amplify the ocular hypotensive effect of forskolin: Statistical design, characterization and in vivo studies. Int. J. Biol. Macromol. 2018, 116, 648-663. [CrossRef] [PubMed]

23. Alam, M.; Hossain, S.; Bhadra, S.; Kumar, U.; Rouf, A.A.S. Development and validation of RP-HPLC method for quantitation of clarithromycin in matrix tablet dosage form. Dhaka Univ. J. Pharm. Sci. 2017, 16, 69-75. [CrossRef] 
24. Sharma, M.; Gupta, N.; Gupta, S. Implications of designing clarithromycin loaded solid lipid nanoparticles on their pharmacokinetics, antibacterial activity and safety. RSC Adv. 2016, 6, 76621-76631. [CrossRef]

25. Fotaki, N.; Brown, W.; Kochling, J.; Chokshi, H.; Miao, H.; Tang, K.; Gray, V. Rationale for selection of dissolution media: Three case studies. Dissolut. Technol. 2013, 20, 6-13. [CrossRef]

26. Zhang, Y.; Huo, M.; Zhou, J.; Zou, A.; Li, W.; Yao, C.; Xie, S. DDSolver: An Add-In Program for Modeling and Comparison of Drug Dissolution Profiles. AAPS J. 2010, 12, 263-271. [CrossRef]

27. Mittal, G.; Sahana, D.K.; Bhardwaj, V.; Ravi Kumar, M.N.V. Estradiol loaded PLGA nanoparticles for oral administration: Effect of polymer molecular weight and copolymer composition on release behavior in vitro and in vivo. J. Control. Release 2007, 119, 77-85. [CrossRef]

28. Martín-Banderas, L.; Alvarez-Fuentes, J.; Durán-Lobato, M.; Prados, J.; Melguizo, C.; Fernandez-Arevalo, M.; Holgado, M.A. Cannabinoid derivate-loaded PLGA nanocarriers for oral administration: Formulation, characterization, and cytotoxicity studies. Int. J. Nanomed. 2012, 7, 5793-5806.

29. Palacio, J.; Orozco, V.H.; López, B.L. Effect of the molecular weight on the physicochemical properties of poly(lactic acid) nanoparticles and on the amount of ovalbumin adsorption. J. Braz. Chem. Soc. 2011, 22, 2304-2311. [CrossRef]

30. Nafee, N.; Schneider, M.; Schaefer, U.F.; Lehr, C.-M. Relevance of the colloidal stability of chitosan/PLGA nanoparticles on their cytotoxicity profile. Int. J. Pharm. 2009, 381, 130-139. [CrossRef]

31. Gupta, R.B. Fundamentals of drug nanoparticles. In Nanoparticle Technology for Drug Delivery; Gupta, R.B., Kompella, U.B., Eds.; Taylor \& Francis Group: New York, NY, USA, 2006; pp. 1-18.

32. Büyükköroğlu, G.; Şenel, B.; Başaran, E.; Yenilmez, E.; Yazan, Y. Preparation and in vitro evaluation of vaginal formulations including siRNA and paclitaxel loaded SLNs for cervical cancer. Eur. J. Pharm. Biopharm. 2016, 109, 174-183. [CrossRef] [PubMed]

33. Emami, J.; Mohiti, H.; Hamishehkar, H.; Varshosaz, J. Formulation and optimization of solid lipid nanoparticle formulation for pulmonary delivery of budesonide using Taguchi and Box-Behnken design. Res. Pharm. Sci. 2015, 10, 17-33. [PubMed]

34. Müller, R.H.; Mäder, K.; Gohla, S. Solid lipid nanoparticles (SLN) for controlled drug delivery-a review of the state of the art. Eur. J. Pharm. Biopharm. 2000, 50, 161-177. [CrossRef]

35. Chronopoulou, L.; Massimi, M.; Giardi, M.F.; Cametti, C.; Devirgillis, L.C.; Dentini, M.; Palocci, C. Chitosan-coated PLGA nanoparticles: A sustained drug release strategy for cell cultures. Colloids. Surf. B Biointerfaces 2013, 103, 310-317. [CrossRef] [PubMed]

36. Wang, Y.; Li, P.; Kong, L. Chitosan-modified PLGA nanoparticles with versatile surface for improved drug delivery. AAPS Pharm. Sci. Tech. 2013, 14, 585-592. [CrossRef] [PubMed]

37. Öztürk, A.A.; Yenilmez, E.; Yazan, Y. Dexketoprofen trometamol-loaded Eudragit ${ }^{\circledR}$ RL 100 nanoparticle formulation, characterization and release kinetics. Acta Pharm. Sci. 2019, 57, 69-84.

38. Öztürk, A.A.; Güven, U.M.; Yenilmez, E. Flurbiprofen Loaded Gel Based Topical Delivery System: Formulation and In Vitro Characterization with New Developed UPLC Method. Acta Pharm. Sci. 2018, 65, 81-105. [CrossRef]

39. Öztürk, A.A.; Güven, U.M. Cefaclor monohydrate loaded microemulsion formulation for topical application: Characterization with new developed UPLC method and stability study. J. Res. Pharm. 2019, 23, 426-440. [CrossRef]

40. Panyam, J.; Williams, D.; Dash, A.; Leslie-Pelecky, D.; Labhasetwar, V. Solid-state solubility infuences encapsulation and release of hydro-phobic drugs from PLGA/PLA nanoparticles. J. Pharm. Sci. 2004, 93, 1804-1814. [CrossRef]

41. Parveen, S.; Sahoo, S.K. Long circulating chitosan/PEG blended PLGA nanoparticle for tumor drug delivery. Eur. J. Pharmacol. 2011, 670, 372-383. [CrossRef]

42. Singh, P.K.; Sah, P.; Meher, J.G.; Joshi, S.; Pawar, V.K.; Raval, K.; Singh, Y.; Sharma, K.; Kumar, A.; Dube, A.; et al. Macrophage-targeted chitosan anchored PLGA nanoparticles bearing doxorubicin and amphotericin B against visceral leishmaniasis. RSC Adv. 2016, 6, 71705-71718. [CrossRef]

43. Fredenberg, S.; Wahlgren, M.; Reslow, M.; Axelsson, A. The Mechanisms of Drug Release in Poly (Lactic-Co-Glycolic Acid)-Based Drug Delivery Systems-A Review. Int. J. Pharm. 2011, 15, 34-52. [CrossRef] [PubMed] 
44. de Azevedo, C.R.; Stosch, M.; Costa, M.S.; Ramos, A.M.; Cardoso, M.M.; Danhier, F.; Préat, V.; Oliveira, R. Modeling of the burst release from PLGA micro and nanoparticles as function of physicochemical parameters and formulation characteristics. Int. J. Pharm. 2017, 532, 229-240. [CrossRef] [PubMed]

45. Huang, X.; Brazel, C.S. On the importance and mechanisms of burst release in matrix-controlled drug delivery systems. J. Control. Release 2001, 73, 121-136. [CrossRef]

46. Yang, H.; Li, J.; Patel, S.K.; Palmer, K.E.; Devlin, B.; Rohan, L.C. Design of Poly (lactic-co-glycolic Acid) (PLGA) Nanoparticles for Vaginal Co-Delivery of Griffithsin and Dapivirine and Their Synergistic Effect for HIV Prophylaxis. Pharmaceutics 2019, 11, 184. [CrossRef] [PubMed]

47. Öztürk, A.A.; Çinar, N.İ.; Yenilmez, E. Development of nano-sized ketoprofen lysine incorporated Eudragit@S100 nanomedicine by double emulsion solvent evaporation and in vitro characterization. J. Pharm. Pharmacogn. Res. 2019, 7, 47-58.

48. Abdelghany, S.; Parumasivam, T.; Pang, A.; Roediger, B.; Tang, P.; Jahn, K.; Britton, W.J.; Chan, H.K. Alginate modified-PLGA nanoparticles entrapping amikacin and moxifloxacin as a novel host-directed therapy for multidrug-resistant tuberculosis. J. Drug Deliv. Sci. Technol. 2019, 52, 642-651. [CrossRef]

49. Kırımlığlu, G.Y.; Öztürk, A.A. Levocetirizine dihydrochloride loaded chitosan nanoparticles: Formulation and in vitro evaluation. Turk. J. Pharm. Sci. 1-20. [CrossRef]

50. Nair, K.L.; Jagadeeshan, S.; Nair, S.A.; Kumar, G.S. Biological evaluation of 5-fluorouracil nanoparticles for cancer chemotherapy and its dependence on the carrier. PLGA. Int. J. Nanomed. 2011, 6, 1685-1697.

51. Vega, E.; Gamisans, F.; Garcia, M.L.; Chauvet, A.; Lacoulonche, F.; Egea, M.A. PLGA Nanospheres for the Ocular Delivery of Flurbiprofen: Drug Release and Interactions. J. Pharm. Sci. 2008, 97, 5306-5317. [CrossRef]

52. Gamisans, F.; Lacoulonche, F.; Chauvet, A.; Espina, M.; Garcia, M.L.; Egea, M.A. Flurbiprofen-loaded nanospheres: Analysis of the matrix structure by thermal methods. Int. J. Pharm. 1999, 179, 37-48. [CrossRef]

53. Gong, H.; Geng, S.; Zheng, Q.; Wang, P.; Luo, L.; Wang, X.; Zhang, Y.; He, H.; Tang, X. An intravenous clarithromycin lipid emulsion with a high drug loading, H-bonding and a hydrogen-bonded ion pair complex exhibiting excellent antibacterial activity. Asian J. Pharm. Sci. 2016, 2, 618-630. [CrossRef]

54. Younes, I.; Rinaudo, M. Chitin and Chitosan Preparation from Marine Sources. Structure, Properties and Applications. Mar. Drugs 2015, 13, 1133-1174. [CrossRef] [PubMed]

55. Öztürk, A.A.; Güven, U.M.; Yenilmez, E.; Şenel, B. Effects of different derivatives of Eudragit polymer on entrapment efficiency, in vitro dissolution, release kinetics and cell viability results on extended release flurbiprofen loaded nanomedicines. Lat. Am. J. Pharm. 2018, 37, 1981-1992.

56. Liu, X.F.; Guan, Y.L.; Yang, D.Z.; Li, Z.; Yao, K.D. Antimicrobial action of chitosan and carboxymethylated chitosan. J. Appl. Polym. Sci. 2001, 79, 1324-1335.

57. Zivanovic, S.; Basurto, C.C.; Chi, S.; Davidson, P.M.; Weiss, J. Molecular Weight of Chitosan Influences Antimicrobial Activity in Oil-in-Water Emulsions. J. Food Protect. 2004, 67, 952-959. [CrossRef] [PubMed]

58. Oroujzadeh, N.; Delpazir, E.; Shariatinia, Z. Studying the effect of particle size on the antibacterial activity of some N-nicotinyl phosphoric triamides. Part. Sci. Technol. 2018, 37, 423-429. [CrossRef]

59. Yamamoto, O. Influence of particle size on the antibacterial activity of zinc oxide. Int. J. Inorg. Mater. 2001, 3, 643-646. [CrossRef]

60. Öztürk, A.A.; Aygül, A.; Şenel, B. In uence of glyceryl behenate, tripalmitin and stearic acid on the properties of clarithromycin incorporated solid lipid nanoparticles (SLNs): Formulation, characterization, antibacterial activity and cytotoxicity. J. Drug Deliv. Sci. Technol. 2019, 54, 101240. [CrossRef]

61. Clinical and Laboratory Standards Institute (CLSI). Performance Standards for Antimicrobial Susceptibility Testing, 29th ed.; CLSI standard M100: Wayne, PA, USA, 2017.

62. Kashi, T.S.; Eskandarion, S.; Esfandyari-Manesh, M.; Marashi, S.M.; Samadi, N.; Fatemi, S.M.; Atyabi, F.; Eshraghi, S.; Dinarvand, R. Improved drug loading and antibacterial activity of minocycline-loaded PLGA nanoparticles prepared by solid/oil/water ion pairing method. Int. J. Nanomed. 2012, 7, 221-234.

(C) 2019 by the authors. Licensee MDPI, Basel, Switzerland. This article is an open access article distributed under the terms and conditions of the Creative Commons Attribution (CC BY) license (http://creativecommons.org/licenses/by/4.0/). 